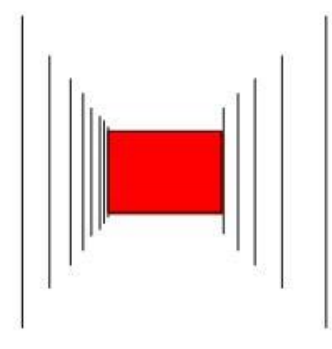

Centre for

Building

Performance

Research

\title{
Exploring Methods for Quantifying Density.
}

A systematic review-based study that evaluates how density is defined and quantified in practice.

Isabella Lum

Nilesh Bakshi

Brenda Vale

Daniele Abreu e Lima

Nick Barratt-Boyes

Research and publication by the

Centre for Building Performance Research,

Victoria University of Wellington.

In partnership with:

Studio of Pacific Architecture.

February 2019 
Edition information

ISBN 978-0-475-12428-9

Authors: Isabella Lum, Nilesh Bakshi, Brenda Vale, Daniele Abrue e Lima, Nick Barratt-Boyes Research Assistants: Isabella Lum.

Partnering Researchers: The Research Group at Studio of Pacific Architecture

Report title. Establishing Existing Methods For Quantifying Density: A systematic review based study that evaluates how density is defined and quantified in practice

Centre for Building Performance Research,

Victoria University of Wellington,

P.O. Box 600, Wellington, New Zealand.

Phone + 6444636200 Facsimile + 6444636204 


\section{PREFACE}

This report presents the findings of the joint research project 'Exploring Methods of Quantifying Density'.

\section{ACKNOWLEDGMENTS}

This work was funded by the joint investment of Studio of Pacific Architecture and the Victoria University of Wellington through the Victoria Summer Research Scholarship Programme.

This work is made possible by the valued efforts of the partnering researchers from the research group at Studio of Pacific Architecture.

NOTES 
$\begin{array}{ll}\text { Preface } & 4\end{array}$

Acknowledgments $\quad 4$

Notes $\quad 4$

$\begin{array}{lr}\text { Introduction } & 6\end{array}$

$\begin{array}{ll}\text { Research questions } & 6\end{array}$

$\begin{array}{ll}\text { Research method } & 6\end{array}$

Direction changes $\quad 6$

Literature Review

Case study Analysis $\quad 8$

Background: Precedent Studies of density quantification $\quad 8$

Density quantification internationally 8

Density quantification within New Zealand 26

SUmmary of research gaps $\quad 31$

Case study analysis

Selected case studies $\quad 31$

Analysis method $\quad 37$

$\begin{array}{ll}\text { Territory definitions and distributions } & 37\end{array}$

Relating territory proportions to scale $\quad 46$

Typical density metrics (Populations, dwellings and buildings) 46

Discussion - medium density results

Implications $\quad 51$

Future Research based on findings and methodlogy limitations. 51

Final list of Limitations

References $\quad 52$

International quantification methods cited $\quad 52$

New Zealand metrics and methods cited $\quad 52$

Case study references $\quad 53$

Other references $\quad 53$

$\begin{array}{ll}\text { Appendix } & 54\end{array}$

Appendix 1 - Summaries of Key Literature $\quad 54$ 


\section{INTRODUCTION}

This paper examines existing methods of defining urban density in terms of their ability to represent New Zealand housing, given the move to densification. New Zealand's housing density is intensifying and diversifying. Reflecting this, Wellington's Urban Development Strategy requires $60 \%$ of housing built from 2001-2051 to be within already developed and reasonably dense areas. Household composition is diversifying. This, along with other density factors, makes the concept of residential density both complex and pertinent. Increased understanding and appropriate management are critical.

Typical density metrics are rough tools used to predict and control land use to improve urban environments. However, understanding these beyond their ratio format is hindered by loose and oversimplified relationships with the physical and perceived urban environment. Therefore, this research aims to understand and clarify some of these correlations and definitions, specifically for New Zealand.

An examination of national literature and research demonstrates a concerning simplicity in the use of New Zealand density quantifications. Housing is classified as low, medium, or high density and commonly defined by dwellings per hectare or by typology, if it is defined at all. Furthermore, these definitions vary between regions and organisations. Thus, this research identifies international precedents of density quantification and applies them to New Zealand housing case studies. The aim is to find which measurements are useful in describing the relationship of the measurement to the New Zealand current housing context.

\section{RESEARCH QUESTIONS}

- How is urban housing density quantified internationally?

- How is urban housing density quantified in New Zealand?

- What does an improved method of density analysis, that allows comparison between regions, involve for New Zealand?

\section{RESEARCH METHOD}

As New Zealand's housing landscape shifts to one with denser and more diverse housing, it is crucial that the metrics used to assess and regulate housing areas are adequate in both ease of use and depth of information. Therefore, this research aims to contribute to an understanding of density quantification techniques and their use in New Zealand. Density quantification is studied through two main methods; literature review and case study analysis. The split strategy is essential. It allows an understanding of existing density quantification methods to be collated first, to inform a preliminary investigation of barriers and primary factors for density quantification and comparison in New Zealand.

\section{DIRECTION CHANGES}

Discuss changes in method throughout

\section{Was originally going to be an analysis of density relationship \\ Then of housing density in New Zealand over time, now that is further research due to time available.}




\begin{abstract}
Change from systematic to narrative literature review.
Very limited review scope, literally just the definitions, metrics and limitations, no discussion of effects etc. or perceptive density (could list some types but that would be about it) Analysis of density metrics through case studies to develop a cross comparison method to understand density in New Zealand, because current definitions are vague and ambiguous about the variables being measured.
\end{abstract}

\title{
LITERATURE REVIEW
}

The review had four main objectives; to create a bibliography of density quantification methods within New Zealand, to collate a bibliography of density quantification methods internationally, to understand the limitations of existing methods and to understand the relationships between the quantification methods and factors. To achieve this, two narrative review searches were undertaken with one focussed on international methods and the other restricted to the methods used in New Zealand. The inclusion of techniques developed in international research is vital due to urban density being a relatively new concern in New Zealand, hence the local understanding and research of density is not comprehensive and has many critical gaps.

For international literature, an initial search was conducted within the Victoria University of Wellingtons library, identifying the key reference 'The urban density assemblage: modelling multiple measures' (Dovey and Pafka, 2014) from the database ProQuest. A knowledgeable academic also provided the two key references 'Understanding Density and High Density' (Cheng, 2010) and 'Compact Cities' (Garcia and Vale, 2017). This allowed a snowball reference search to follow to identify further relevant publications. The references of the three key papers were surveyed for other relevant titles (i.e. those which discussed urban density metrics or analysis methods) from which the abstracts were checked to confirm the papers relevance and the snowball process continued. A narrative search technique was essential in finding relevant literature as database searches for this topic are difficult. This is due to the diverse and broad use of the term density and the overabundance of research that uses urban, residential or population density without contributing to the understanding of the metrics. See appendix one for a full list of the most relevant literature.

The review of New Zealand methods followed a more systematic survey of databases of the national organisations which publish relevant research, namely; BRANZ (including their medium-density housing website), Wellington City Council, Auckland City Council, Knowledge Auckland and Ministry for the Environment.

Significance level assessment for national literature:

1. Relevant topic (e.g. MDH, intensification, infill, housing planning)

2. Regulation of density through other metrics (e.g. yard setbacks)

3. Discusses existing urban density

4. Discusses techniques of urban density quantification

5. Has a definition of low, medium or high density (a density quantification)

Key words for national literature: density measurement, medium density, density metric, intensification 


\section{CASE STUDY ANALYSIS}

Following the literature review, a new density analysis method is investigated that aims to enable us to understand New Zealand's unique density situation and to make meaningful comparisons. New Zealand's current understanding of urban density is incredibly crude. The metrics used lack the depth to inform meaningful decisions by providing arbitrary, ambiguous and rather ineffectual measures. Therefore, the new density analysis method investigates what factors are crucial to representing New Zealand's urban density as well as the relevance of applying precedent measurement techniques.

\section{BACKGROUND: PRECEDENT STUDIES OF DENSITY QUANTIFICATION}

\section{DENSITY QUANTIFICATION INTERNATIONALLY}

The concept of urban density has undergone extensive research and development, providing New Zealand with a vast multiplicity of quantification and analysis precedents. (Cheng, 2010, p. 4; Churchman, 1999, p. 390; Dovey and Pafka, 2014, p. 70; Rapoport, 1975, p. 136) Despite this work, there is no consensus of which method is best, and combining the various density concepts has proven difficult and impractical for industry use. (Boyko and Cooper, 2011; Cheng, 2010; Churchman, 1999; Dovey and Pafka, 2014, p. 66) This is largely due to different methods being developed for the extraction of different information. Therefore, the following research seeks to gather and understand as many of these methods of analysis and quantification as possible, allowing a comprehensive analysis of existing methods of quantification.

Preservation and creation of urban amenity through the regulation of density is long-established, standard practice for urban planning. (Cheng, 2010, p. 5; Dovey and Pafka, 2014, p. 72) Various controls, which will be discussed later, are employed to either limit density for safety, open space, infrastructure load, traffic, overcrowding and sunlight, or encourage density for safety, creativity, economic performance, environmental performance, social interaction, street life vitality, walkability and public transport efficiency. (Cheng, 2010, pp. 5-8; Dovey and Pafka, 2014, p. 71) This has developed extensive literature on urban density that focuses on the effects of density, rather than the quantifications themselves. (Boyko and Cooper, 2011; Cheng, 2010; Dovey and Pafka, 2014) However, this is outside of the scope of this research and will not be discussed in depth.

Density measurement principally involves calculating the ratio of the quantification of one urban variable, to another. Kim Dovey and Elek Pafka (2014, pp. 66-68) categorise these variables under three headings; buildings, populations and open space, to which networks and territories can also be added. (Berghauser Pont and Haupt, 2010) This provides the basis of the structure of this review which addresses metrics in a logical fashion. Discussion begins with clarifying territories, which are crucial to all other density metrics, then moves through different techniques based on their relative relations and levels of complexity.

\section{PERCEIVED DENSITY}

Perceived density is urban density described and emphasized through human perception and interaction, rather than metrics and maths. (Cheng, 2010, p. 12; Churchman, 1999, p. 390; Dovey and Pafka, 2014, p. 67) Because perceived density can only be quantified in a subjectively, rather than objectively, analysis of its concepts is outside the scope of this research. They will still be briefly explained to enable tentative discussion of the merits of different density metrics, due to their relations to perceived density. However, it is vital to remember these relations are variable, especially 
for planners and others who use density metrics as a tool to influence perceived densities and other qualities. (Cheng, 2010, p. 12; Dovey and Pafka, 2014, p. 67)

When density is perceived, it is understood as a level of intensity incorporating concepts of buzz, interaction and dynamics. (Dovey and Pafka, 2014, p. 67) Intensity in physics is a measure of the energy movement within the space that is often generated by concentrated matter, rather than of the concentration of the matter itself. (Dovey and Pafka, 2014, p. 67) This follows Churchmans (1999, p. 400) explanation of urban intensity as a concept perceived through environmental cues of activity and people:

Physical variables are hypothesized to be related to perceived density by affecting the number of physical sensory stimuli in an environment that indicate the actual or potential presence of people. These physical variables include tight or open spaces; intricate or simple spaces; large or small building height to space ratios; numerous or few signs, lights, cars, and people (or their traces); the predominance of artificial versus natural elements or smells; high or low noise levels; and the presence or absence of non-residential or mixed land uses. (Churchman, 1999, p. 401)

Any two individuals will then assess these physical variables differently due to their own sociocultural values and other situational characteristics. (Churchman, 1999, p. 401)

In terms of types of perceived density, spatial and social density are distinguished in psychology (Cheng, 2010, p. 12; Churchman, 1999, p. 390), but definitions from sociology and urban theory interact with both. (Cheng, 2010, p. 12; Dovey and Pafka, 2014, p. 67) Early dialogue of density in sociology defines the notions of dynamic density by Durkhiem "as a concentration of socially meaningful relationships" (Dovey and Pafka, 2014, p. 67) and of visual density by Sennett as a level of social diversity. (Dovey and Pafka, 2014, p. 67) Both of these describe the concentration of types of people and interactions within a space. Investigations in urban theory by Jacobs developed the concept of buzz, involving an understanding of the differing social atmospheres that are often related to a certain locale. (Dovey and Pafka, 2014, p. 67)

Commonly discussed in urban theory is crowding, often thought of as an effect of high density. (Dovey and Pafka, 2014, p. 67) A typical misconception about crowding is the degree of subjectivity involved in its assessment. (Churchman, 1999, p. 398; Dovey and Pafka, 2014, p. 67) Crowding is a state of psychological stress induced by a negative evaluation of the social density that is heightened by individual factors and stressors. (Cheng, 2010, p. 12; Dovey and Pafka, 2014, p. 67) It is not actually correlated with a high built density at all and although population density can be a factor, it cannot cause overcrowding independently. (Cheng, 2010, p. 12) 


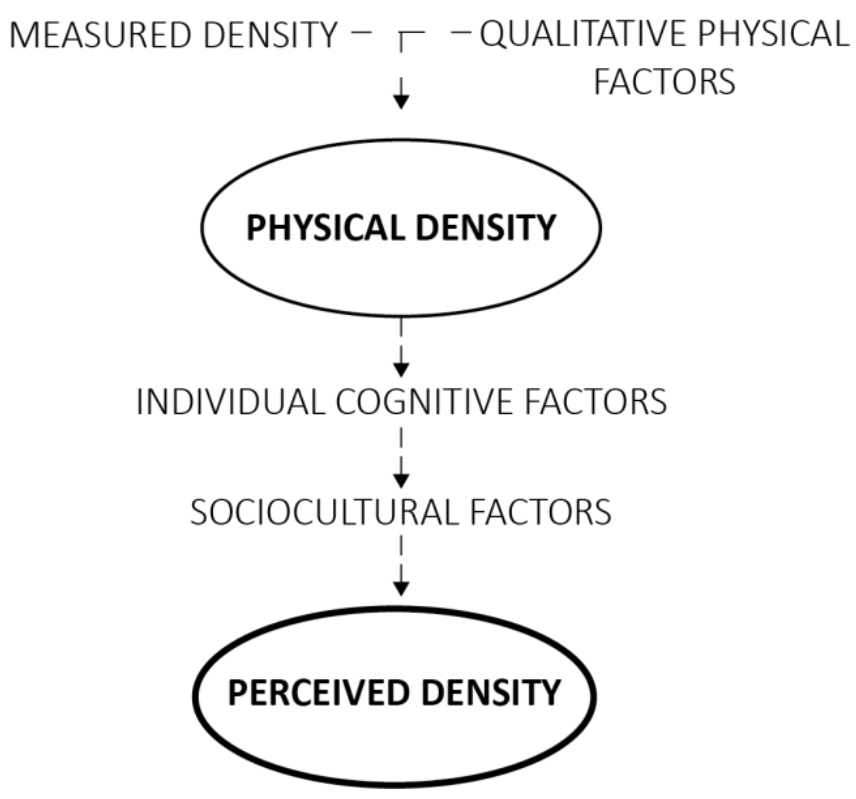

Figure X: Perceived density factors, adapted from Alexanders (1993, p. 183) diagram

\section{TERRITORY AND SCALE}

No matter what kind of density is being explored it is vital to establish the type and scale of the territory of the measurement, providing the necessary precision for density comparisons. The common way to distinguish territories is by using net and gross measures. Dovey and Pafka (2014, p. 67) clarify these as follows; "net density being calculated within a development site and gross density incorporating the broader network of public space". However, these definitions are still highly ambiguous and vary between organisations and locations. (Boyko and Cooper, 2011; Dovey and Pafka, 2014 , p. 67) A range of net and gross territory definitions have been identified and approximately organised from the smallest to the largest in scale in the table below. Territories which had the same definition are combined for clarity, but it is important to note that all definitions were repeated between multiple resources with many variant titles and most titles also had several different definitions. This highlights the concerning amount of ambiguity involved in the quantification of density.

\begin{tabular}{|c|c|c|}
\hline Territory title & Definition & Visual \\
\hline Interior & $\begin{array}{l}\text { The area within buildings. This can be the total floor space, } \\
\text { limited to a type of building (e.g. residential) or limited to } \\
\text { certain internal spaces, like habitable rooms or bedrooms. } \\
\text { The type of internal space used needs to be clearly defined, } \\
\text { but literature does not discuss or further define this territory } \\
\text { past internal built space. }\end{array}$ & \\
\hline Net Plot & $\begin{array}{l}\text { The sum of all buildable plot areas, excluding area that isn't } \\
\text { developable. }\end{array}$ & Developable \\
\hline Plot & Legal plot area only, including area that is undevelopable. & Plot \\
\hline Gross Plot & $\begin{array}{l}\text { The legal plot area, half the area of adjacent roads and a } \\
\text { quarter of the area of adjacent intersections. If the width of }\end{array}$ & Plot + road \\
\hline
\end{tabular}




\begin{tabular}{|c|c|c|}
\hline & $\begin{array}{l}\text { the adjacent roads is greater than } 30.5 \mathrm{~m} \text {, then only the area } \\
\text { the road up to } 15.2 \mathrm{~m} \text { in width is used to omit space that } \\
\text { serves arterial functions. }\end{array}$ & \\
\hline Net Island & $\begin{array}{l}\text { The area of the urban 'block' comprised of multiple } \\
\text { contiguous private properties that are surrounded by public } \\
\text { space (which includes public roads). }\end{array}$ & Block \\
\hline Gross Island & $\begin{array}{l}\text { The area of the urban 'block' comprised of multiple } \\
\text { contiguous private properties that are surrounded by public } \\
\text { space (which includes public roads), including the area of half } \\
\text { the area of the surrounding streets. }\end{array}$ & Block + road \\
\hline Net Fabric & $\begin{array}{l}\text { Gross plot area for multiple, adjacent plots. This measure can } \\
\text { be applied at any scale but only includes the sum of the areas } \\
\text { of the legal plots (not areas such as roads). This is often } \\
\text { applied to just residential plots to provide a residential } \\
\text { density measure. }\end{array}$ & Multiple plots \\
\hline Fabric & $\begin{array}{l}\text { "Fabric' incorporates a larger pattern of streets and blocks } \\
\text { (at varying scales) where the fabric is of homogenous function } \\
\text { and density" (Pont and Haupt, 2010, p. 71). A common } \\
\text { example of a fabric scale territory is residential land or } \\
\text { neighbourhood land. }\end{array}$ & $\begin{array}{l}\text { Multiple plots }+ \\
\text { roads }+ \text { other } \\
\text { areas }\end{array}$ \\
\hline Gross Fabric & $\begin{array}{l}\text { The area of a specific urban fabric as above, but not excluding } \\
\text { space for facilities which serve the wider region such as zoos } \\
\text { and commercial activity. }\end{array}$ & $\begin{array}{l}\text { Multiple plots }+ \\
\text { roads }+ \text { all other } \\
\text { areas }\end{array}$ \\
\hline City & $\begin{array}{l}\text { The area of the urbanised or contiguous built-up area of the } \\
\text { city, not including undeveloped land. }\end{array}$ & \\
\hline Metropolis & $\begin{array}{l}\text { Bounded by the jurisdictional boundaries, including } \\
\text { undeveloped areas. }\end{array}$ & \\
\hline
\end{tabular}

To label territories as either net or gross is clearly not comprehensive enough as eleven different and reasonably precise definitions were able to be extracted from the full range found (see appendix for the full table). Dovey and Pafka (2014, p. 71) state that "the distinction between gross and net is a relative rather than absolute distinction between scales". But, as demonstrated by the definitions above, net and gross are more of a distinction between the space types included and can be applied to any scale. The territories fall under six area types in a spectrum from the most net to the most gross measures as follows; interior space, developable space, legal plot space, legal plot space and adjacent roading, partly inclusive space and completely inclusive space. These can then be implemented within any chosen scale from the part plot to the metropolis. This vast range of territory options requires both the inclusion of spaces and scale to be clearly defined for all density measures to negate misunderstanding. (Dovey and Pafka, 2014, p. 71) It has been suggested that the range of scales can be categorised into the four intervals plot, island, fabric and region. (Pont and Haupt, 2010, p. 85) However, this is impractical as these intervals aren't absolute scales, have ambiguous boundaries and are based on certain westernised urban morphologies, so cannot be applied accurately for comparisons. 
Dovey and Pafka (2014, p. 71) argue for density to be analysed using a multi-scalar method to enable an understanding of the density relations between scales. This would be beneficial as urban density does not have the even distribution and homogenous space that single scale averages imply. For larger scale territories these relations become especially pertinent because as the scale increases, "spatial heterogeneity increases to incorporate different functions, open space, access networks and interstitial space" (Dovey and Pafka, 2014, p. 71). Assuming these scalar relationships would provide inaccurate measures. Nevertheless, multi-scalar analysis is still uncommon due to the lack of clarity and efficiency of representation. The multi-scalar analysis methods that exist will be discussed in a later section.

As demonstrated, territory itself is a complicated and ambiguous matter that often prohibits accurate representation and comparison for density metrics. Both the scale and inclusion criteria of the territory used needs to be explicitly defined to negate misrepresentation and misinterpretation of measures. Net and gross do not provide enough information as distinctions as both have been identified by literature to refer to any of the six area types defined here. Furthermore, the base territories of measurements need to be identical or the contextually specific scalar relationships must be known for comparisons of measures to be possible. It is also important to note that these territories found do not define external spaces within the singular developable plot which demonstrates a bizarre distancing of urban density metrics from the human scale, the very thing they claim to affect.

\begin{tabular}{|c|c|c|c|c|}
\hline $\begin{array}{l}\text { Variable } \\
\text { categories }\end{array}$ & Names & $\begin{array}{l}\text { Parameters } \\
\text { or equation }\end{array}$ & $\begin{array}{l}\text { Intended and } \\
\text { actual } \\
\text { understanding }\end{array}$ & Source \\
\hline $\begin{array}{l}\text { Built } \\
\text { volume/space }\end{array}$ & $\begin{array}{l}\text { - Dwelling density } \\
\text { - Household units per } \\
\text { hectare }\end{array}$ & $\begin{array}{l}\text { Dwellings / } \\
\text { land area }\end{array}$ & $\begin{array}{l}\text { Density of housing } \\
\text { units, based off } \\
\text { legal ownership } \\
\text { titles not individual } \\
\text { building forms }\end{array}$ & $\begin{array}{l}\text { (Alexander, 1993, } \\
\text { p. 186; Boyko and } \\
\text { Cooper, 2011, p. } \\
\text { 4; Dovey and } \\
\text { Pafka, 2014, p. 67) }\end{array}$ \\
\hline $\begin{array}{l}\text { Built } \\
\text { volume/space }\end{array}$ & - Building density & $\begin{array}{l}\text { Buildings / } \\
\text { land area }\end{array}$ & $\begin{array}{l}\text { Density of building } \\
\text { units, based off } \\
\text { individual building } \\
\text { forms }\end{array}$ & $\begin{array}{l}\text { (Alexander, 1993, } \\
\text { p. 186; Boyko and } \\
\text { Cooper, 2011, p. } \\
\text { 4) }\end{array}$ \\
\hline $\begin{array}{l}\text { Built } \\
\text { volume/space }\end{array}$ & $\begin{array}{l}\text { - Bed space density } \\
\text { - Bedroom density }\end{array}$ & $\begin{array}{l}\text { Bedrooms / } \\
\text { land area }\end{array}$ & $\begin{array}{l}\text { Density of bed } \\
\text { spaces, based off } \\
\text { individually } \\
\text { identified } \\
\text { bedrooms }\end{array}$ & $\begin{array}{l}\text { (Alexander, 1993, } \\
\text { p. 186) }\end{array}$ \\
\hline $\begin{array}{l}\text { Built } \\
\text { volume/space }\end{array}$ & $\begin{array}{l}\text { - Habitable room } \\
\text { density }\end{array}$ & $\begin{array}{l}\text { Habitable } \\
\text { rooms / land } \\
\text { area }\end{array}$ & $\begin{array}{l}\text { Density of rooms } \\
\text { used in a dwelling } \\
\text { for dwelling } \\
\text { purposes, excludes } \\
\text { kitchens, }\end{array}$ & $\begin{array}{l}\text { (Boyko and } \\
\text { Cooper, 2011, p. } \\
\text { 4) }\end{array}$ \\
\hline
\end{tabular}




\begin{tabular}{|c|c|c|c|c|}
\hline & & & $\begin{array}{l}\text { bathrooms and } \\
\text { WCs }\end{array}$ & \\
\hline People & $\begin{array}{l}\text { - Population density } \\
\text { - Residential density } \\
\text { - Regional density } \\
\text { - Job density }\end{array}$ & $\begin{array}{l}\text { Population / } \\
\text { land area }\end{array}$ & $\begin{array}{l}\text { Density of people } \\
\text { over the total land } \\
\text { area }\end{array}$ & $\begin{array}{l}\text { (Alexander, 1993, } \\
\text { p. 186; Boyko and } \\
\text { Cooper, 2011, pp. } \\
\text { 4-5; Cheng, 2010, } \\
\text { p. 4; Dovey and } \\
\text { Pafka, 2014, p. 67) }\end{array}$ \\
\hline
\end{tabular}

Averaging the number of instances of a chosen variable over an area of land is the simplest and one of the most common ways of quantifying density. (Cheng, 2010, p. 4; Dovey and Pafka, 2014, p. 67) In all fields where urban density is relevant, dwelling density and population density dominate as the selected metrics. (Alexander, 1993, p. 185; Boyko and Cooper, 2011, p. 3; Dovey and Pafka, 2014, p. 66) Their simplicity in calculation is beneficial for efficiency of use and ease of comprehension. However, the majority of existing analyses caution against the use of these reductive techniques, especially over larger areas, as their scope for misinterpretation and misrepresentation is immense. (Cheng, 2010, p. 4; Dovey and Pafka, 2014, p. 67) Although much of the ambiguity that accompanies these metrics can be quelled through the inclusion of explicit definitions, oversimplifying the urban environment into singular averages in still dangerous. (Alexander, 1993, p. 191; Boyko and Cooper, 2011, p. 7; Pont and Haupt, 2010, p. 341)

Some literature argues for dwelling density to be used over population density, as its lower rate of change is believed to make it a more accurate and reliable density representation. (Pont and Haupt, 2010, p. 258) But population density simply communicates different information. Population density has an inherent temporal dimension as varying proportions of populations, such as residents, visitors, workers and commuters, are present at different times of day. (Dovey and Pafka, 2014, p. 69) Dwelling density is also specifically identified in literature as being relied on too heavily by policy, human geography and planning, which implies assumptions of certain relationships between dwelling and population density. (Boyko and Cooper, 2011, p. 3; Dovey and Pafka, 2014, p. 67) This is a dangerous due to "the lack of direct relationship between the density of buildings and residential populations due to variability in household size, dwelling size and the proportion of non-dwelling uses" (Dovey and Pafka, 2014, p. 68). These relationships vary widely between contexts, both temporally and by location. (Boyko and Cooper, 2011, p. 3; Dovey and Pafka, 2014, p. 68) Hence, any conversions between population and dwelling densities would be inaccurate.

The largest criticism of these simple per area averages is their reductionist approach of only addressing an aspect of a singular variable. Dovey and Pafka $(2014$, p. 75$)$ explain further:

Urban density is not a property of buildings or people but of spatial relations between them... no single density measure or variable can be considered apart from the larger assemblage... While the relations between particular density measures may be systematic, the significant emergent outcomes are not so predictable. It is a mistake to treat density as one thing when it is a multiplicity; it is a mistake to see density in terms of buildings, people or open spaces when it is a set of conjunctions between them.

Simple averages remove the variable from its urban relations and factors, counteractively weakening the metrics' relationships with perceived density. (Alexander, 1993, p. 191; Dovey and Pafka, 2014, p. 
75) The oversimplification prevents meaningful density representation and restricts the quantification of a three-dimensional assemblage to a one-dimensional metric. (Boyko and Cooper, 2011, p. 7; Dovey and Pafka, 2014, p. 68)

Ultimately, the oversimplification involved in these averages is both the greatest advantage and the detriment of these density quantification techniques. Their clear benefit is that any variable, depending on what is most situationally appropriate, can be easily selected to calculate a density measure. However, they also require the separation of relations that are vital for meaningful representation of density. They cannot begin to touch on perceived density concepts without reference to more than one density factor. For example, when dwelling density is separated from the factor of house size, therefore its spatial relationship to open space, it cannot address built intensity as the metric implies. Additionally, these factors cannot be accurately assumed without rigorous and contextually specific analysis. Averaging the number of people, dwellings, buildings, bedrooms or habitable rooms across land area alone, provides a quantification technique with very weak relationships to perceived density. So, these methods provide a useful aspect of density analysis, however the incorporation or clarification of other relevant factors and relationships is essential for accurate representation.

\begin{tabular}{|c|c|c|c|c|}
\hline $\begin{array}{l}\text { Variable } \\
\text { categories }\end{array}$ & Names & Parameters or equation & $\begin{array}{l}\text { Intended and actual } \\
\text { understanding }\end{array}$ & Source \\
\hline Space & - Tare & $\begin{array}{l}\text { (total land area - non- } \\
\text { net space) / total land } \\
\text { area }\end{array}$ & $\begin{array}{l}\text { The difference in } \\
\text { area as a ratio } \\
\text { between net and } \\
\text { gross measures of a } \\
\text { territory }\end{array}$ & $\begin{array}{l}\text { (Pont and } \\
\text { Haupt, 2010) }\end{array}$ \\
\hline $\begin{array}{l}\text { Built or } \\
\text { people } \\
\text { Space }\end{array}$ & $\begin{array}{l}\text { Density } \\
\text { profile }\end{array}$ & $\begin{array}{l}\text { Selected density plotted } \\
\text { over an area through a } \\
\text { series of measurements }\end{array}$ & $\begin{array}{l}\text { Indication } \\
\text { settlement } \\
\text { structure }\end{array}$ & $\begin{array}{l}\text { (Cheng, } \\
\text { 2010) }\end{array}$ \\
\hline $\begin{array}{l}\text { Built or } \\
\text { people } \\
\text { Space }\end{array}$ & $\begin{array}{l}\text { Density } \\
\text { gradient }\end{array}$ & $\begin{array}{l}\text { (Density of external } \\
\text { location - Density of } \\
\text { centre location) / } \\
\text { Distance of the external } \\
\text { location from the } \\
\text { central location }\end{array}$ & $\begin{array}{l}\text { Population } \\
\text { distribution in } \\
\text { relation to the town } \\
\text { centre to show the } \\
\text { level of } \\
\text { centralisation or } \\
\text { sprawl }\end{array}$ & $\begin{array}{l}\text { (Cheng, } \\
\text { 2010) }\end{array}$ \\
\hline
\end{tabular}

The average measures discussed above imply a reasonably even distribution of density within the measured area, which is not often true. (Cheng, 2010, p. 6) Although not used as widely, there are some multi-scalar metrics which address this; density gradient and density profile. (Cheng, 2010, p. 7)

Density gradient provides a measure of the rate of change of density, over a distance. (Cheng, 2010, p. 7) This is usually with reference to an urban centre, from which density is measured in concentric rings as they radiate outward. (Cheng, 2010, p. 7) The comparison of density gradients over time is very beneficial as it can highlight movement and spatial evolution. (Cheng, 2010, p. 7) This is demonstrated in figure $X$, drawn by Cheng $(2010$, p. 7), which displays two different density and 
migration scenarios. The first, on the left, shows decentralisation as the density gradient becomes progressively less steep and the graph on the right shows centralisation where the density also increases throughout the whole territory whilst the borders expand. (Cheng, 2010, p. 7) The main limitation of density gradients is the assumption that population distribution is even around its rings. For a city such as Wellington, where density is highly influenced by the topography, a concentrically averaged gradient will likely misrepresent the situation.

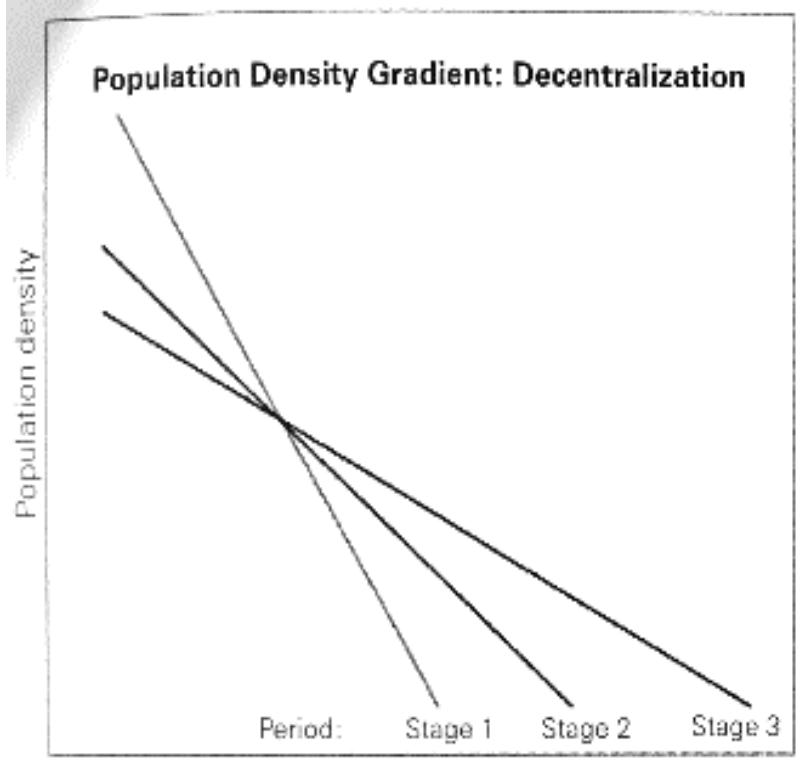

Distance from town centre

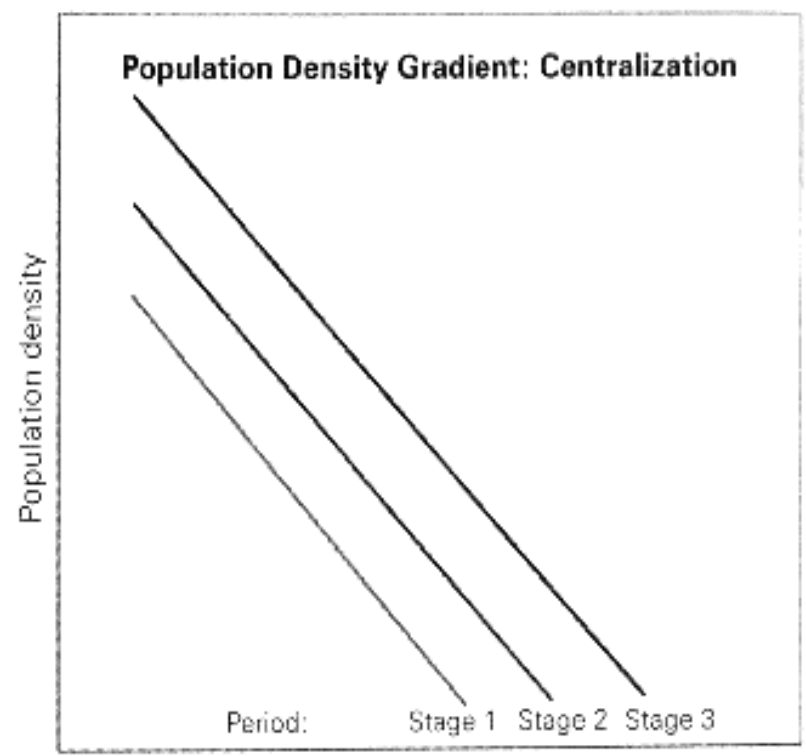

Distance from town centre

Density profile allows an indication of settlement structure by visually plotting the densities over an area. (Cheng, 2010, p. 7) This can either be done in a grid format as shown in figure $X$, or by region as shown in figure $X$ of Hong Kong. (Cheng, 2010, p. 8) This technique allows a visual representation that is clearly communicates relative densities within an area, though comparatively to other quantification methods it requires a lot of time and data to generate. (Cheng, 2010, p. 8) It provides a rural classification system in the UK that allows comparison of settlement structures to predefined profiles. (Cheng, 2010, p. 8) However, this is achieved through averaging densities within concentric circles, similar to density gradients, hence the issues with assumptions and simplification discussed
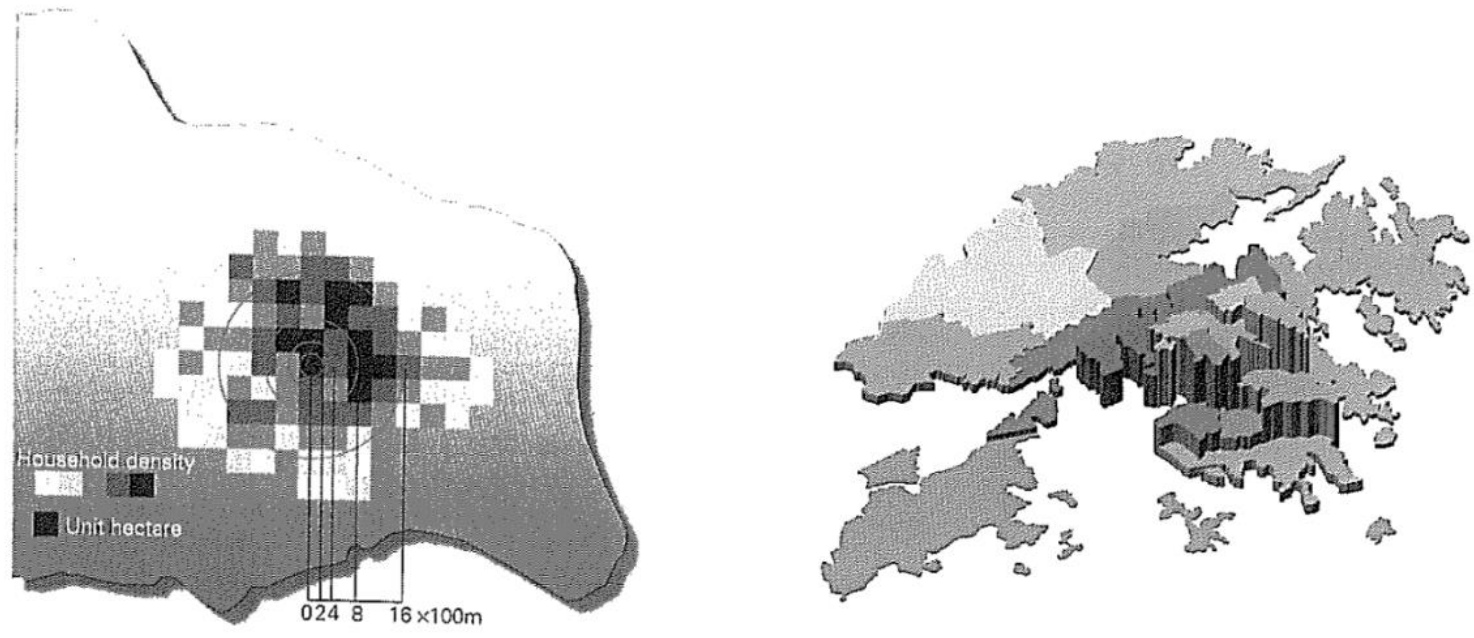
above still applies. (Cheng, 2010, p. 8) Additionally, the predefined profiles need to be diverse and contextually relevant to allow adequate classification. (Cheng, 2010, p. 8)

Tare is another measure that addresses multiple scales, but through territory differences rather than density distribution. (Pont and Haupt, 2010, p. 109) Tare was conceptualised by Pont and Haupt (2010, p. 109) and is the difference in area of two different territories or scales, as shown in figure $X$ which displays the tare between different territories in red. Although tare is not typically a density measure in itself, it can be used to provide a ratio measure of the density of a space type within another. (Pont and Haupt, 2010, p. 103) It would also be highly beneficial for density comparisons of larger territories if the tare between the base measurement area and the more net territory was stated. It would facilitate understandings of factors such as the influence of the public network. (Pont and Haupt, 2010, p. 103)

.

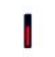

Tare 60\%

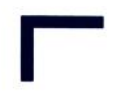

Building

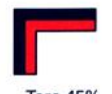

Tare 45\%
Lot

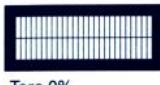

Tare 0\%

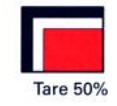

Island
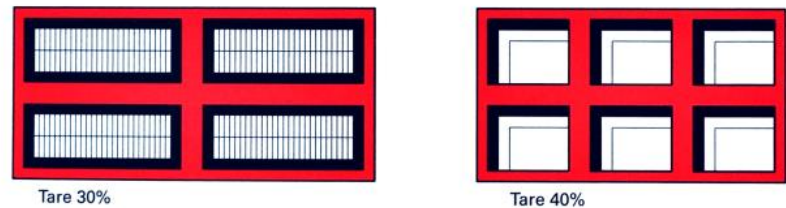

Fabric

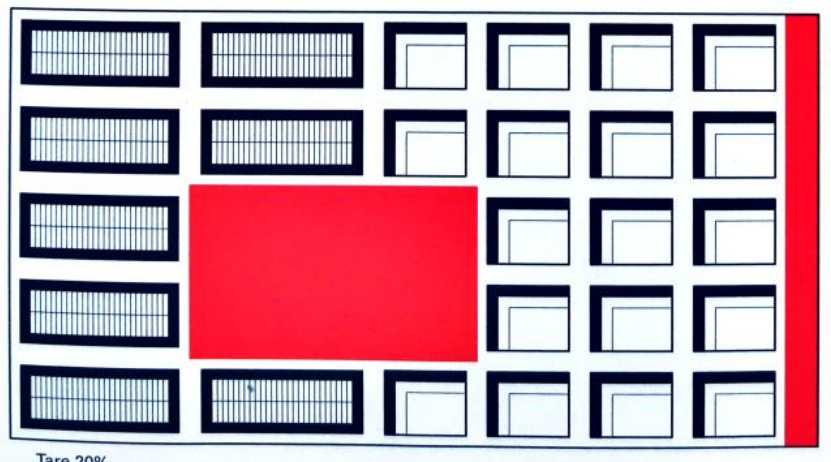

District

Tare space of the

areas at each leve

Tare 20\% 


\begin{tabular}{|c|c|c|c|c|}
\hline $\begin{array}{l}\text { Variable } \\
\text { categories }\end{array}$ & Names & $\begin{array}{l}\text { Parameters or } \\
\text { equation }\end{array}$ & $\begin{array}{l}\text { Intended and actual } \\
\text { understanding }\end{array}$ & Source \\
\hline Public space & - Network density & $\begin{array}{l}\text { Length of } \\
\text { network / land } \\
\text { area }\end{array}$ & $\begin{array}{l}\text { A measure of } \\
\text { network } \\
\text { interconnectivity of } \\
\text { a particular network }\end{array}$ & $\begin{array}{l}\text { (Pont and } \\
\text { Haupt, 2010, } \\
\text { p. 96) }\end{array}$ \\
\hline Public space & - Mesh & $\begin{array}{l}2 \text { / (length of } \\
\text { network / land } \\
\text { area) }\end{array}$ & $\begin{array}{l}\text { A measure of } \\
\text { network } \\
\text { interconnectivity of } \\
\text { a particular network } \\
\text { represented as the } \\
\text { distance from street } \\
\text { to street if the } \\
\text { network density is } \\
\text { applied in a square } \\
\text { grid fabric }\end{array}$ & $\begin{array}{l}\text { (Pont and } \\
\text { Haupt, 2010, } \\
\text { p. 98) }\end{array}$ \\
\hline
\end{tabular}

Pont and Haupt (2010, p. 96) suggest network density to aid the incorporation of scale into density metrics, through an understanding of the urban fabrics permeability. Network density can be applied to any network type including internal, external, pedestrian, bicycle and motor networks as a general list and this must be explicitly defined for the measure to be meaningful. (Pont and Haupt, 2010, p. 96) They declare that "adding network density as a primary indicator of the density concept increases the latter's capacity to indicate important primary measurements of the urban landscape and describe important aspects of urban form" (Pont and Haupt, 2010, p. 98). They believe this due to the networks inherent role of both dividing and integrating private space through public access ways. (Pont and Haupt, 2010, p. 98) Dovey and Pafka (2014, p. 71) critique this and question the assumption that measuring total street length is the best way to quantify permeability, offering other variables such as intersections and blocks. This is clearly an area of density that needs further investigation.

\section{URBAN MORPHOLOGY AND DENSITY}

Density metrics are often used for their expected relationship with urban form. (Alexander, 1993, p. 182) Urban research that investigates these peculiar relations between density metrics and controls and the resulting morphologies have largely been prevalent in the last two decades. (Dovey and Pafka, 2014, p. 67) Dwelling, population and network density have an incredibly loose and limited interaction with the resulting built fabric that they are attempting to influence. (Alexander, 1993, p. 182; Churchman, 1999, p. 392) The built space ratios provide more control, however unless they are used in conjunction with each other their influence is still very limited. (Cheng, 2010, pp. 8-10; Pont and Haupt, 2010, pp. 90-93)

Alexander (1993, pp. 182-190) investigated and analysed the relationship with dwelling density (which he refers to as net dwelling density) by testing the relationships through a range of systematically generated, theoretical housing layouts. This is shown in figure $\mathrm{X}$ where the theoretical 
case studies are grouped by housing type and plotted by dwelling density. (Alexander, 1993, p. 193) It is important to note that he has not included what he regards as unconventional layouts, such as zero-lot housing, and has only extended the lower density limits of schemes to include what he deems are "reasonable design configurations" (Alexander, 1993, p. 194). He found that the upper ranges of certain typologies confirmed popular, assumed, associations. (Alexander, 1993, p. 194) However, the lower ranges completely overlap and it is possible to have common densities between many building types (Alexander, 1993, p. 194). This supports Churchman's (1999, p. 392) statement that "although high-rise buildings are intuitively associated with high residential density, there is no necessary relationship between the two". Building types can only indicate a possibility of differing density ranges. Additionally, Alexander's (1993, p. 194) study was completed over 20 years ago and modern day urban morphologies are much more diverse, weakening the typology to density relationship further.

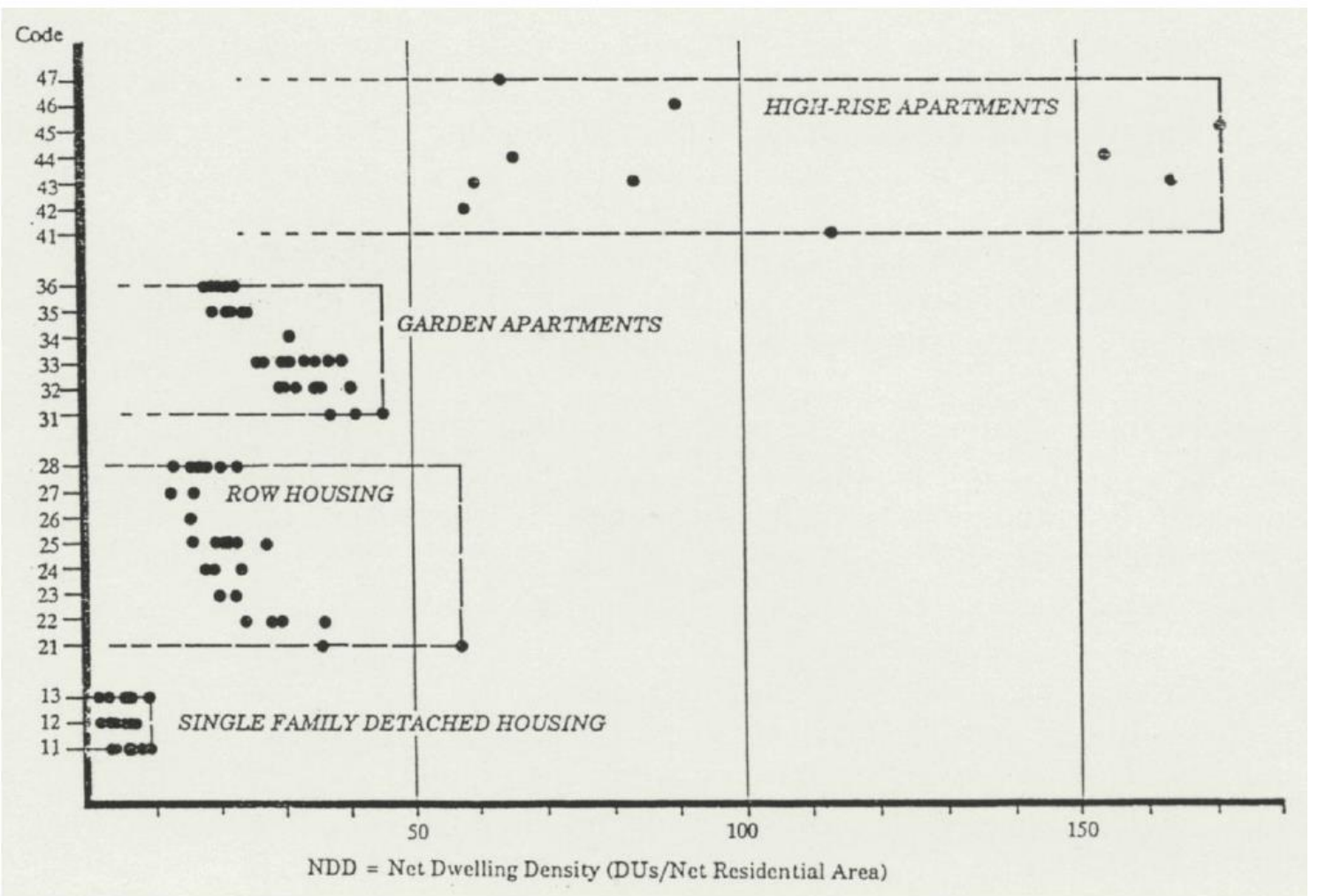

FIGURE 3. Distribution of NDD by dwelling types.

BUILT SPACE RATIOS

\begin{tabular}{|c|c|c|c|c|}
\hline $\begin{array}{l}\text { Variable } \\
\text { categories }\end{array}$ & Names & $\begin{array}{l}\text { Parameters } \\
\text { equation }\end{array}$ & $\begin{array}{l}\text { Intended and } \\
\text { actual } \\
\text { understanding }\end{array}$ & Source \\
\hline $\begin{array}{l}\text { Built } \\
\text { volume/space } \\
\text { Open space }\end{array}$ & $\begin{array}{l}\text { - Floor Area Ratio } \\
\text { (FAR) } \\
\text { - Plot ratio } \\
\text { - Floor space index } \\
\text { (FSI) }\end{array}$ & $\begin{array}{l}\text { Total floor area / } \\
\text { site area }\end{array}$ & $\begin{array}{l}\text { The efficiency of } \\
\text { the site use through } \\
\text { a measure of the } \\
\text { building bulk in }\end{array}$ & $\begin{array}{l}\text { (Cheng, } \\
\text { 2010, p. 5; } \\
\text { Dovey and } \\
\text { Pafka, 2014, } \\
\text { p. 67; Pont }\end{array}$ \\
\hline
\end{tabular}




\begin{tabular}{|c|c|c|c|c|}
\hline & $\begin{array}{l}\text { - Physical density } \\
\text { - Building intensity }\end{array}$ & & $\begin{array}{l}\text { relation to the plot } \\
\text { size }\end{array}$ & $\begin{array}{l}\text { and Haupt, } \\
2010, \text { p. } 87 \text { ) }\end{array}$ \\
\hline $\begin{array}{l}\text { Built } \\
\text { volume/space } \\
\text { Open space }\end{array}$ & $\begin{array}{l}\text { - Site coverage } \\
\text { - Ground space } \\
\text { index (GSI) }\end{array}$ & $\begin{array}{l}\text { Building footprint } \\
\text { area / site area }\end{array}$ & $\begin{array}{l}\text { The relationship } \\
\text { between built and } \\
\text { non-built space of a } \\
\text { site }\end{array}$ & $\begin{array}{l}\text { (Pont and } \\
\text { Haupt, 2010, } \\
\text { p. 91) }\end{array}$ \\
\hline $\begin{array}{l}\text { Built } \\
\text { volume/space }\end{array}$ & $\begin{array}{l}\text { - Floor Space Index } \\
\text { (FSI) } \\
\text { - Built intensity }\end{array}$ & $\begin{array}{l}\text { Total floor area / } \\
\text { building footprint } \\
\text { area }\end{array}$ & $\begin{array}{l}\text { The potential } \\
\text { efficiency of use of } \\
\text { the built space } \\
\text { created }\end{array}$ & $\begin{array}{l}\text { (Pont and } \\
\text { Haupt, 2010, } \\
\text { p. 87) }\end{array}$ \\
\hline $\begin{array}{l}\text { Built } \\
\text { volume/space } \\
\text { Open space }\end{array}$ & $\begin{array}{l}\text { - Open Space Ratio } \\
\text { (OSR) } \\
\text { - Land index } \\
\text { - Spaciousness }\end{array}$ & $\begin{array}{l}\text { (Total site area - } \\
\text { Building footprint } \\
\text { area) / total floor } \\
\text { area }\end{array}$ & $\begin{array}{l}\text { The pressure on } \\
\text { non-built space due } \\
\text { to the ratio of } \\
\text { interior space to } \\
\text { exterior space } \\
\text { provided }\end{array}$ & $\begin{array}{l}\text { (Pont and } \\
\text { Haupt, 2010, } \\
\text { p. 92) }\end{array}$ \\
\hline
\end{tabular}

Built space ratios begin to provide more meaningful density metrics by representing the relationships between physical variables. (Boyko and Cooper, 2011, p. 7; Cheng, 2010, pp. 5-6; Dovey and Pafka, 2014, p. 68; Pont and Haupt, 2010, p. 92) Because of this, these measurements are common in urban planning and regulation and are commonly utilised within the plot space. (Boyko and Cooper, 2011, p. 7; Dovey and Pafka, 2014, p. 67) However, they are all still limited as they cannot describe the distribution, use or quality of spaces, they have no scale and can only relate to built variables, providing no indication of populations. (Pont and Haupt, 2010, p. 88) Hence, this results in similar assumptions to those of the simple per area average metrics.

Floor area ratio is the most common density metrics within planning and architecture. (Cheng, 2010, p. 5; Dovey and Pafka, 2014, p. 67) It is considered one of the most unambiguous measures because the variables provide clear territories. (Cheng, 2010, p. 5) Floor area ratio is commonly used to forecast returns and investment while designing by describing the total building bulk. (Boyko and Cooper, 2011, p. 7; Dovey and Pafka, 2014, p. 67; Pont and Haupt, 2010, p. 92) It is more descriptive than the other density quantification methods discussed in this report so far, indicating relative built intensity. (Pont and Haupt, 2010, p. 92) Another positive is that compared to other regulative measures used in planning it allows relative control over physical density without heavy design limitations, so new building typologies can still emerge. (Dovey and Pafka, 2014, p. 67) Conversely, as floor area ratio deals with the total floor area and the total site area, it fails to describe the composition through spaciousness or building height which heavily influence the perceived intensity of space and buildings. (Dovey and Pafka, 2014, p. 67)

The other built ratio commonly used in planning as a density control, is site coverage. (Cheng, 2010, p. 6; Dovey and Pafka, 2014, p. 67) It is often used to regulate density through preserving open space and preventing over-build, to illustrate the resultant pressure on open space for circulation and recreation and to limit the negative effects of solid urban patterns. (Cheng, 2010, p. 6; Dovey and Pafka, 2014, p. 67; Pont and Haupt, 2010, p. 92) Site coverage also allows great flexibility in building design by only describing the area constraints of the building footprint, not the building bulk, shape 
or height. (Dovey and Pafka, 2014, p. 67) However, its relation to perceived density is still inherently flawed by this.

Evidently, much of the discussion about floor area ratio and site coverage also applies to the metric open space ratio, as it is essentially the combination of site coverage, floor area ratio and floor space index. (Cheng, 2010, p. 5) But, as this metric addresses floor space in comparison to left over open space, rather than total site space, it has the ability to inherently describe spaciousness as well as built intensity through total building bulk. (Pont and Haupt, 2010, p. 92)

\begin{tabular}{|c|c|c|c|c|}
\hline $\begin{array}{l}\text { Variable } \\
\text { categories }\end{array}$ & Names & $\begin{array}{l}\text { Parameters } \\
\text { equation }\end{array}$ & $\begin{array}{l}\text { Intended and actual } \\
\text { understanding }\end{array}$ & Source \\
\hline $\begin{array}{l}\text { Built } \\
\text { volume/space } \\
\text { People }\end{array}$ & $\begin{array}{l}\text { - Occupancy rate } \\
\text { - Urban footprint }\end{array}$ & $\begin{array}{l}\text { Floor area / } \\
\text { Population }\end{array}$ & $\begin{array}{l}\text { The built } \\
\text { consumption per } \\
\text { person in a given } \\
\text { area and internal } \\
\text { density, by } \\
\text { measuring the } \\
\text { amount of floor } \\
\text { space available per } \\
\text { person }\end{array}$ & $\begin{array}{l}\text { (Pont and } \\
\text { Haupt, 2010, } \\
\text { p. 86) }\end{array}$ \\
\hline $\begin{array}{l}\text { Built } \\
\text { volume/space } \\
\text { People }\end{array}$ & $\begin{array}{l}\text { - Occupancy } \\
\text { - Internal density }\end{array}$ & $\begin{array}{l}\text { Population } \\
\text { Floor area }\end{array}$ & $\begin{array}{l}\text { The density of people } \\
\text { within a space }\end{array}$ & $\begin{array}{l}\text { (Boyko and } \\
\text { Cooper, } \\
2011 \text {, p. 2; } \\
\text { Dovey and } \\
\text { Pafka, 2014, } \\
\text { p. 68) }\end{array}$ \\
\hline $\begin{array}{l}\text { Built } \\
\text { volume/space } \\
\text { People }\end{array}$ & $\begin{array}{l}\text { - Built-up area per } \\
\text { capita }\end{array}$ & $\begin{array}{l}\text { Building footprint } \\
\text { area / Population }\end{array}$ & $\begin{array}{l}\text { The amount of built } \\
\text { up area per person }\end{array}$ & $\begin{array}{l}\text { (Patel, 2011, } \\
\text { p. 584) }\end{array}$ \\
\hline $\begin{array}{l}\text { People } \\
\text { Public space }\end{array}$ & $\begin{array}{l}\text { - Plot factor } \\
\text { - Street life density } \\
\text { - External density }\end{array}$ & $\begin{array}{l}\text { Population } \\
\text { Public space }\end{array}$ & $\begin{array}{l}\text { The density of people } \\
\text { in public space }\end{array}$ & $\begin{array}{l}\text { (Dovey and } \\
\text { Pafka, 2014, } \\
\text { p. 68) }\end{array}$ \\
\hline $\begin{array}{l}\text { People } \\
\text { Public space }\end{array}$ & $\begin{array}{l}\text { - Public space per } \\
\text { capita } \\
\text { - Public ground area } \\
\text { per capita }\end{array}$ & $\begin{array}{l}\text { Public space / } \\
\text { Population }\end{array}$ & $\begin{array}{l}\text { The amount of public } \\
\text { space per person }\end{array}$ & $\begin{array}{l}\text { (Dovey and } \\
\text { Pafka, 2014, } \\
\text { p. 68) }\end{array}$ \\
\hline
\end{tabular}

Many assume that more built space means a higher population, which is incorrect. (Boyko and Cooper, 2011, p. 79) There is an inherent relation between built space and population, but it is more complex than often assumed and is mediated by household size. (Dovey and Pafka, 2014, p. 69; Pont and Haupt, 2010, p. 79) For example, These metrics provide this spatial relation as an average, either internally or externally. (Dovey and Pafka, 2014, p. 70) As with the prior metrics they are limited by the inability to describe distributions. (Dovey and Pafka, 2014, p. 70) Additionally, they are limited by the fact that populations exist in a space according to urban rhythms, so all populations cannot simply be totalled 
for an accurate value and the population used will describe approximate densities for specific situations. (Dovey and Pafka, 2014, p. 70)

Occupancy rate and occupancy are simply inverse measures that describe the density of people within built space. (Dovey and Pafka, 2014, p. 69; Pont and Haupt, 2010, p. 81)

\begin{tabular}{|c|c|c|c|c|}
\hline $\begin{array}{l}\text { Variable } \\
\text { categories }\end{array}$ & Names & $\begin{array}{l}\text { Parameters } \\
\text { equation }\end{array}$ & $\begin{array}{l}\text { Intended and } \\
\text { actual } \\
\text { understanding }\end{array}$ & Source \\
\hline $\begin{array}{l}\text { Built } \\
\text { space/volume } \\
\text { People } \\
\text { Public space } \\
\text { Open space }\end{array}$ & $\begin{array}{l}\text { - Patel's modelled } \\
\text { method }\end{array}$ & $\begin{array}{l}\text { Floor Space index, } \\
\text { Built up area per } \\
\text { capita, net density, } \\
\text { gross density }\end{array}$ & $\begin{array}{l}\text { Clarification of the } \\
\text { inter-relationships } \\
\text { between Patel's } \\
\text { fundamental } \\
\text { parameters and } \\
\text { urban layouts. A } \\
\text { tool to aid the } \\
\text { design of desirable } \\
\text { urban layouts } \\
\text { within density. }\end{array}$ & (Patel, 2011) \\
\hline $\begin{array}{l}\text { Built } \\
\text { space/volume } \\
\text { People } \\
\text { Public space } \\
\text { Open space }\end{array}$ & $\begin{array}{l}\text { - Dovey and Pafka's } \\
\text { modelled method }\end{array}$ & $\begin{array}{l}\text { Connects all } \\
\text { variables }\end{array}$ & $\begin{array}{l}\text { A multivariable } \\
\text { assemblage of the } \\
\text { relationships of } \\
\text { variables and } \\
\text { quantification } \\
\text { methods }\end{array}$ & $\begin{array}{l}\text { (Dovey and } \\
\text { Pafka, 2014) }\end{array}$ \\
\hline $\begin{array}{l}\text { Built } \\
\text { space/volume } \\
\text { Public space } \\
\text { Open space }\end{array}$ & $\begin{array}{l}\text { - Pont and Haupt's } \\
\text { space matrix }\end{array}$ & $\begin{array}{l}\text { Base Land Area, } \\
\text { Network Length, } \\
\text { Gross Floor Area, } \\
\text { Built Up Area } \\
\text { (Footprint) }\end{array}$ & $\begin{array}{l}\text { A multivariable } \\
\text { definition of } \\
\text { density }\end{array}$ & $\begin{array}{l}\text { (Pont and } \\
\text { Haupt, 2010) }\end{array}$ \\
\hline $\begin{array}{l}\text { Built } \\
\text { space/volume } \\
\text { Public space }\end{array}$ & $\begin{array}{l}\text { - Land use intensity } \\
\text { rating }\end{array}$ & & $\begin{array}{l}\text { A density scale that } \\
\text { relates to } \\
\text { qualitative factors }\end{array}$ & $\begin{array}{l}\text { (Alexander, } \\
1993)\end{array}$ \\
\hline
\end{tabular}

- Many of the more complex methods require complex charts

- All highlight that it is difficult to analyse densities and meaning of metrics without comparison to known typologies

- $\quad$ None have really been taken up by practice due to their complexity

\section{Patel's method}

- Patel connects six primary density measures: FAR to people/HA through Urban Footprint. Then link to open space through Plot Factor. Public space / capita as a predictor of external crowding. Net people/HA from pop/buildable plots. THEN map in complex chart to measure affects on each other. 
- " "Patel (2011) constructs a model that connects six primary density measures as follows. First, he relates FAR to population density (people/hectare) through the measure of total floor area/capita (urban footprint). These measures are then linked to those of open space through a concept he calls the 'plot factor': the ratio of private to public land use. This is then used to measure public space/capita (including streets and parks) as a predictor of external crowding. A net measure of people/hectare is derived from population/buildable plots. These six parameters are then mapped in a complex chart showing how change to any of them affects all the others in a direct and measureable manner." (Dovey and Pafka, 2014, p. 68)

- Patel's chart (Patel, 2011, p. 586) and (Patel, 2011, p. 593)
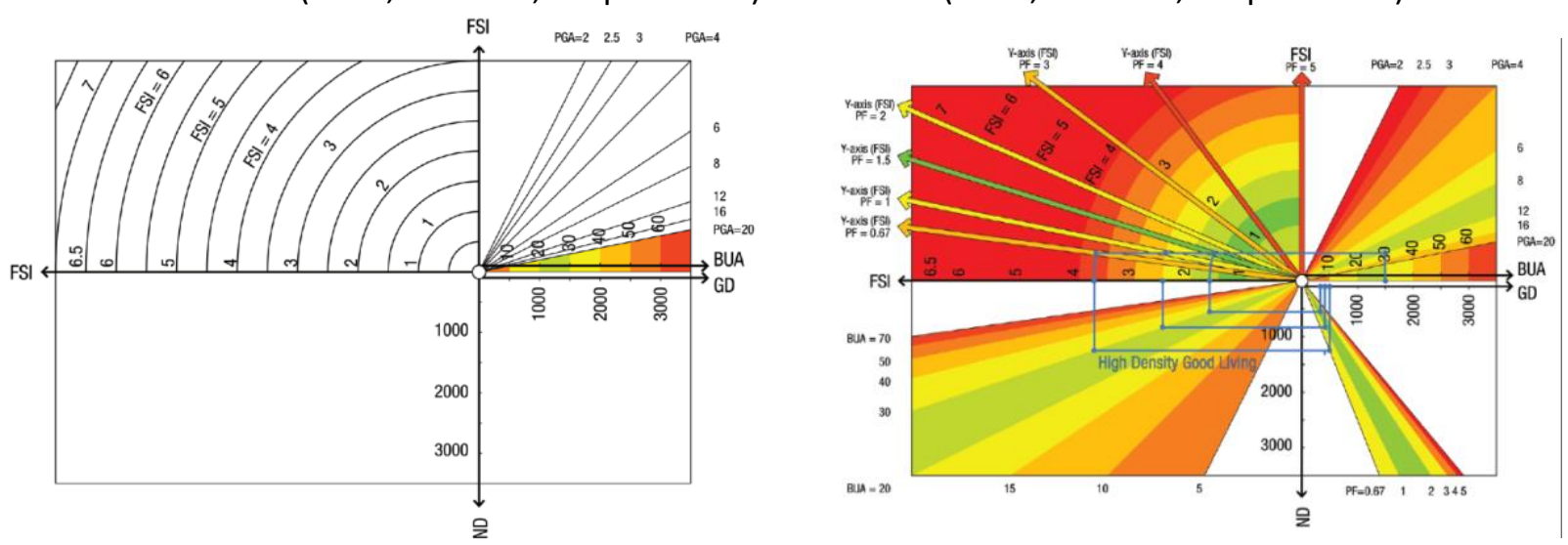

- Intended as a tool for desinging "good" density

\section{Dovey and Pafka's method}

- Kim Dovey and Elek Pafka (2014, pp. 67-69) aim to conceptualise urban density by using an integrative approach to identify, clarify and link the key density concepts and controls. Their model is a matrix using the loose framework of assemblage theory, relating the three fields of density measurements; buildings, populations and open space to scales and intensities. "Our goal is to develop a model that enables us to research questions of density and urban intensity in any urban morphology, particularly to be able to contrast cities of the global north and south, and luxury housing with slums." (Dovey and Pafka, 2014, p. 68)

- Result is the matrix of interrelated variables below (Boxes are the metrics, white arrows are the mediators) 


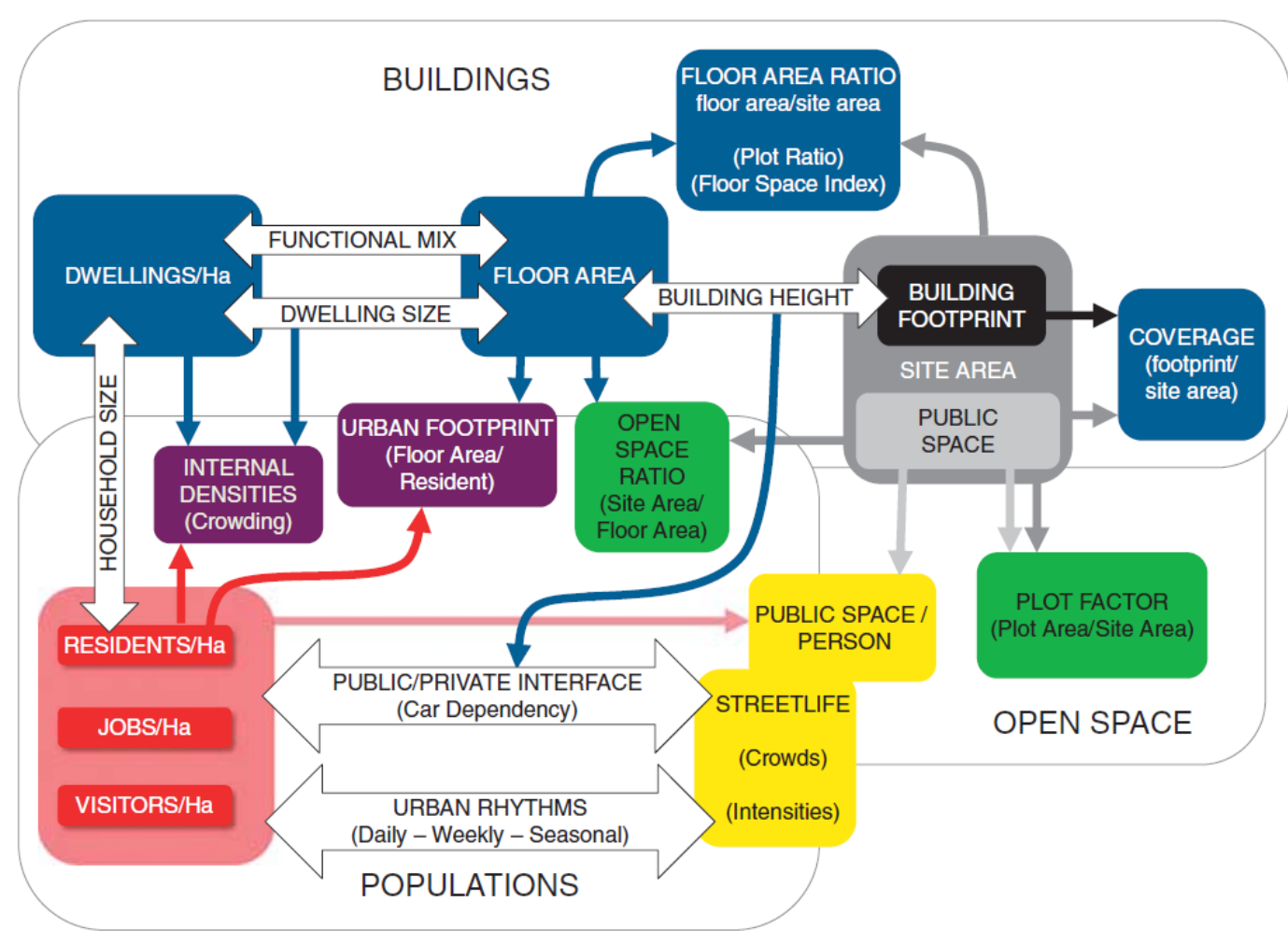

Figure 3: Relating open space to buildings and populations.

- Trialling the model on several morphological profiles produced the below graph (Dovey and Pafka, 2014, p. 74)

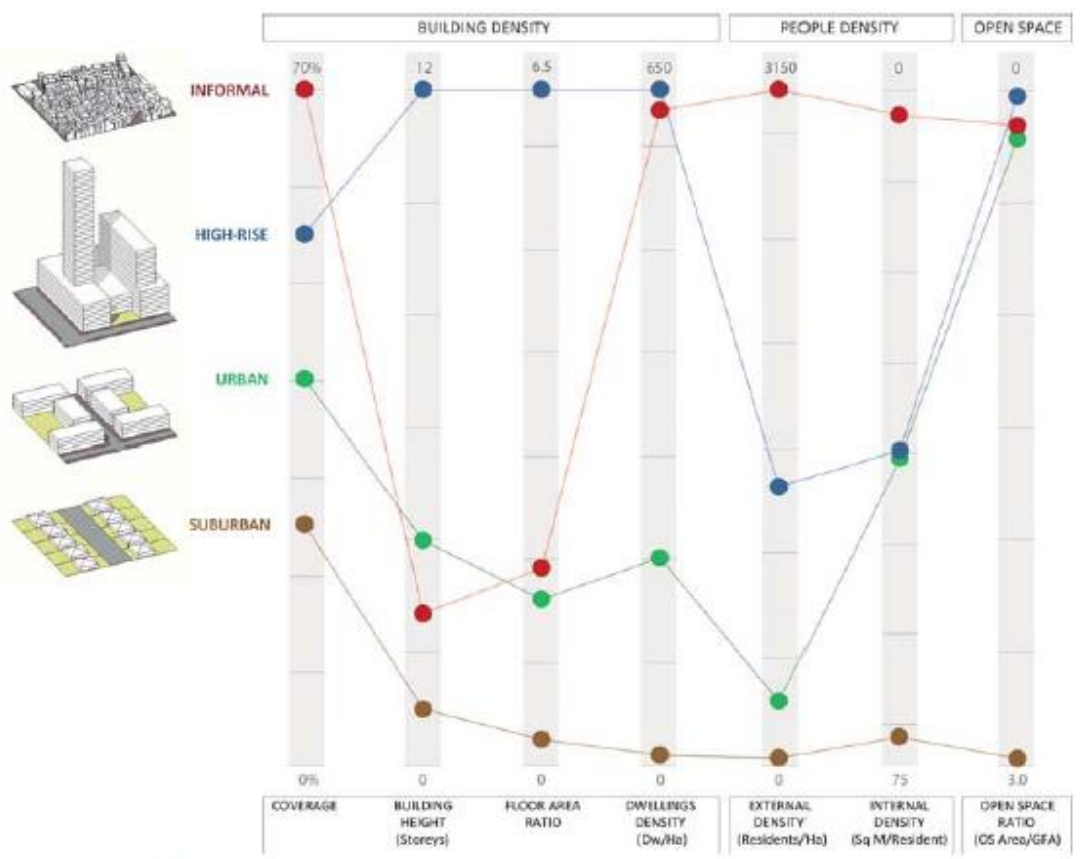

Comparing morphological profiles.

- Dovey and Pafkas main conclusion about re-thinking density and applying density controls:

- "any approach needs to be antireductionist. Urban density is not a property of buildings or people but of spatial relations between them; between buildings, 
between people and also between people and buildings." (Dovey and Pafka, 2014, p. 75)

- "it follows that a focus on any single density control is similarly fraught. Urban design and planning controls such as height, FAR, dwelling density and setback can all be useful in different circumstances and can be applied as minimum, maximum or both. Different controls may be combined to achieve particular effects" (Dovey and Pafka, 2014, p. 75)

- "a point that has been made before but not well learned: density is multi-scalar with different measures and effects operating at different scales. The question of urban density makes little sense before one defines the scale" (Dovey and Pafka, 2014, p. 76)

- "we suggest more attention be paid to the somewhat mysterious relation of density to urban intensity. Depending on how urban design controls in particular are managed, we can produce density without intensity or intensity without high density. There are many kinds of urban intensity and while all depend on certain levels of density, intensity is not a phenomenon that simply increases with building or population densities." (Dovey and Pafka, 2014, p. 76)

\section{Pont and Haupt's method}

- Similar to Pont and Haupt's thinking, but only using what they believe to be the vital, physical variables (not including relations to populations) to understand the built urban fabrics relation with density. The result is a range of complex charts similar to Patel's where the specific examples can be plotted.

- $\quad$ "Pont and Haupt (2010) have developed a matrix of interrelated variables, a multivariate definition of density incorporating relations between total floor area, degrees of land coverage and network morphology. They point out a nest of co-dependent variables linking site coverage, building height and floor areas. A key point of this matrix is to demonstrate the lack of direct relationship between the density of buildings and residential populations due to variability in household size, dwelling size and the proportion of non-dwelling uses (Pont and Haupt, 2010, p. 85)." (Dovey and Pafka, 2014, p. 68)

- Haupt and Pont conclude with a multivariable definition of density (space matrix)

Using the three fundamental indicators:

- Intensity (FSI / floor space index / floor area ratio)

- Compactness (GSI / ground space index / site coverage)

- $\quad$ Network density (N)

- The goal was for this space, matrix to allow definition of urban types without becoming too complicated through over-detailed definitions or too simplified... But it is still pretty complicated!

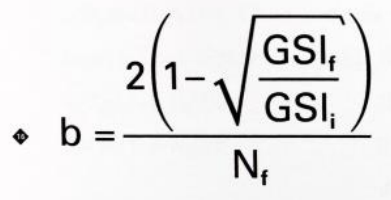

- Resulting equation

(Pont and Haupt, 2010, p. 111) 
- $\quad$ Resulting

charts

to

be

plotted

on

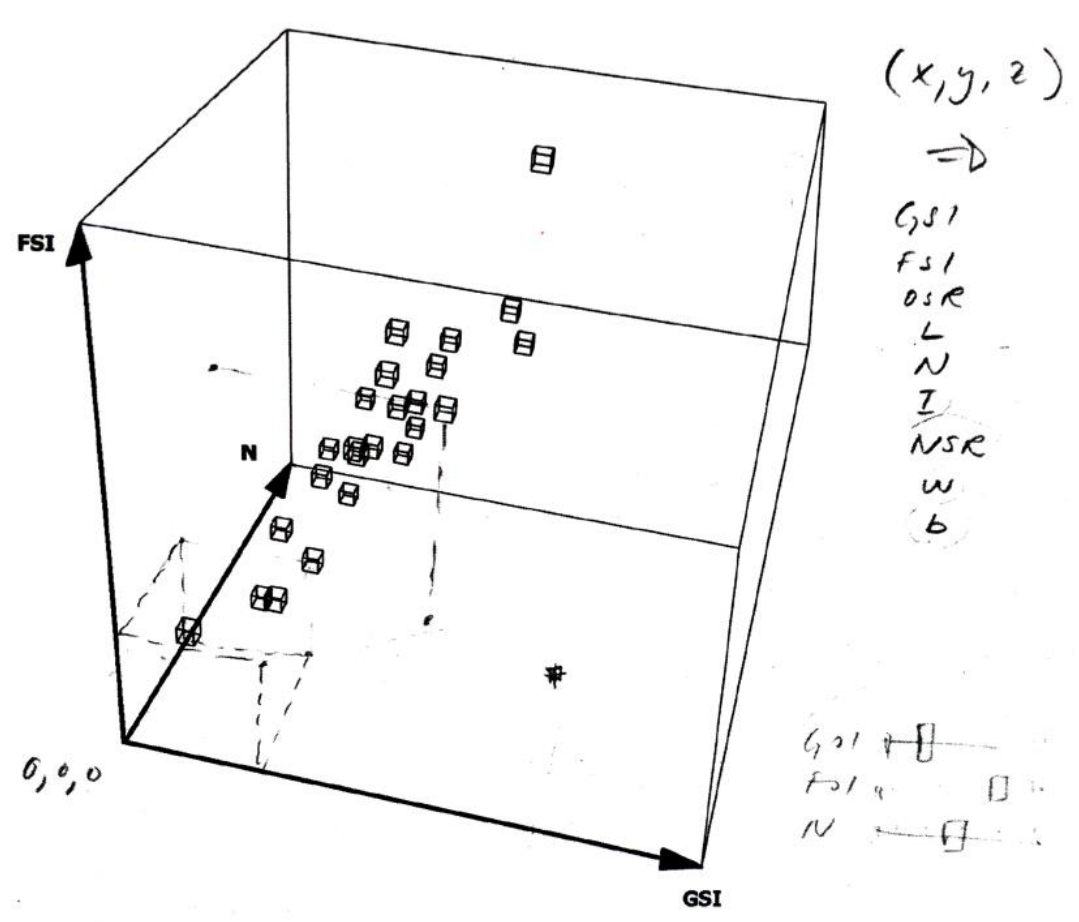

Spacematrix. The

FSI on the z-axis

gives an indication

of the intensity in

an area and the GSI

on the $\mathrm{x}$-axis reflects

its compactness.

The $\mathrm{N}$ on the $\mathrm{y}$-axis

provides us with

information

concerning the

area's network.

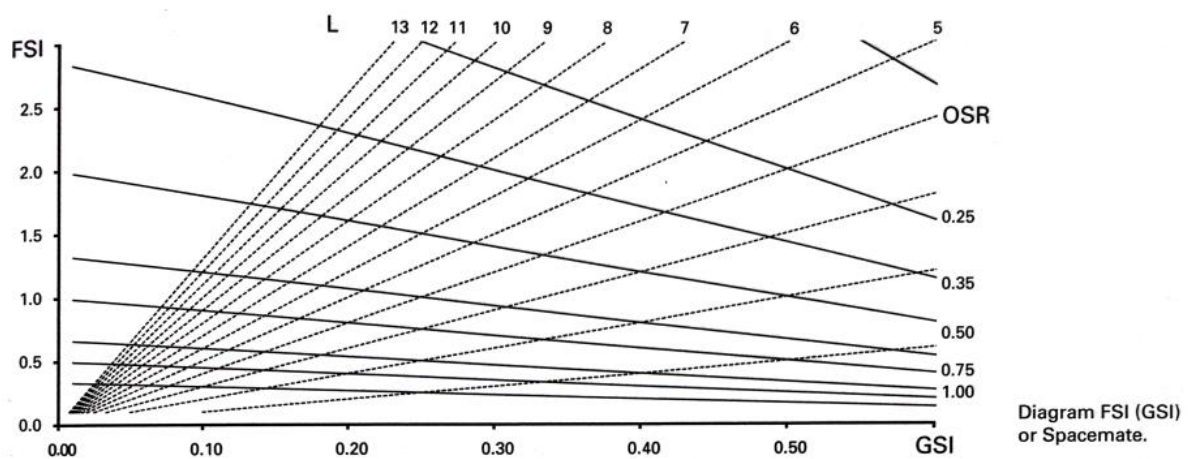

은

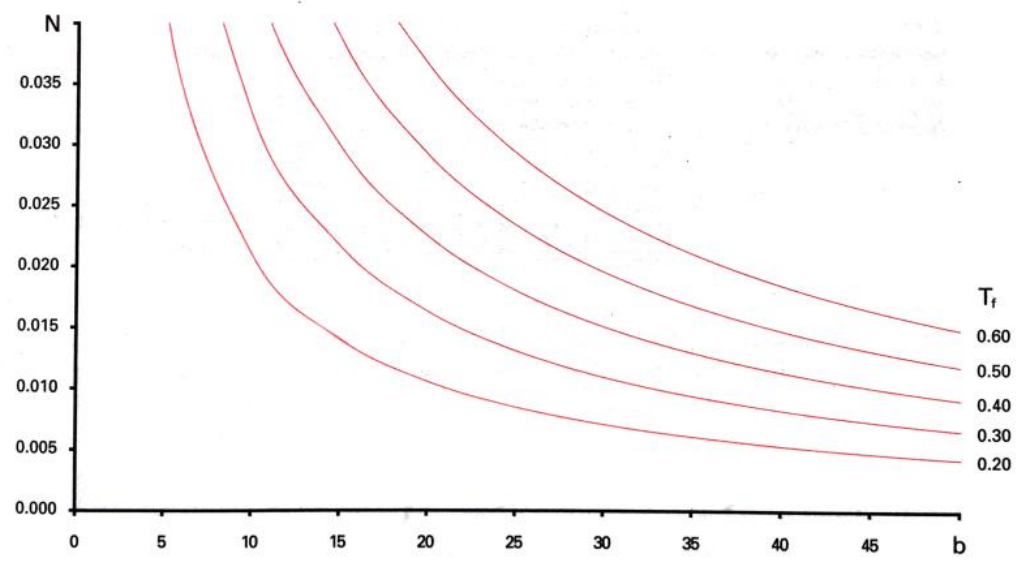

Diagram $\mathrm{N}_{f}$ (b).

(Pont and Haupt, 2010, p. 123)

\section{Land use intensity Ratio}


(Alexander, 1993) p.185 FHA developed: "Land Use Intensity Ratio which combines FAR with five other indexes reflecting open space, living space, recreation, parking." Also incorporated in their densitometer. "1972). The FHA' s claims for its indexes, as more reliable reflections of of a development, are not really supported in practice. Besides their complexity transparency, these measures are also flawed because they build in a set of rigid standards upon which all the relationships are based, and their use has not become widespread"

\section{DENSITY QUANTIFICATION WITHIN NEW ZEALAND}

Housing density is a relatively new concern in New Zealand. It has existed in urban or town planning and analysis since the early 70s, largely for economic purposes and to prevent overcrowding in the more affordable, denser 'flats'. It has arisen as a pertinent issue to planning in the last few decades as housing density has increased and diversified due to a focus on a compact city. Contributing factors include sustainability, diversification of household structure, housing affordability crisis in major cities and lifestyle changes that privilege convenience over privacy and space. Planning documents published outline the criticality of increasing housing density whilst maintaining quality, but never discuss exactly how the density or quality should be measured.

- "Households are getting smaller, the population is ageing, and the city is becoming more ethnically diverse"

- Better neighbourhood design than "post-world war 2 unsustainable suburban subdivisions" (BRANZ, n.d.) is being demanded

\section{METRICS}

Actual quantifications are difficult to find

- Planning documents are largely dependent on regulatory metrics

- Council documents largely discuss density of an area comparatively and locally rather than through metrics. Even when metrics are used, they still vary between suburb classifications

- Largely only MDH definitions provided (logical, because low and high are anything that sit outside of these so can be inferred). Will focus on MDH definitions because of this

In New Zealand, housing density is classified under three main categories; low, medium and high density. The dominant method of describing density is qualitatively, rather than quantitively, by using typological classifications and arbitrary constraints.

- Further than this, dwellings per hectare and people per hectare are overwhelmingly dominating, despite their simplicity and limitations etc.

- The most common method of definition is to provide a typology or vague density at the lower limit and a cap on building height or storeys at the upper (Allen and Bryson, 2017)

The terms low, medium, and high density were commonly used within the literature. These terms are used in two different ways. (Sharpin, 2006)

- New housing developments are often described as being low, medium or high density in style

- Low density style housing is detached, and usually on a generous section.

- Medium density style is semi detached, and up to three storeys in height

- any housing four storeys and over is classified as high density

- Settlement levels across a large suburban area are also often described as being of low, medium or high density. Sometimes, a correlating dwelling density is also given, but overall, 
definitions of density levels are rarely provided. Importantly, it was observed that these can also be relative rather than fixed concepts with HHU/HA being the most common measurement. This Identifies need for a clarification of density measurements in New Zealand.

Of the density definitions found, only two were largely or solely quantitative:

The Department of Internal Affairs defined typical densities as part of a glossary for their study on urban communities (The Department of Internal Affairs, 2008)

a) Low density: 10-25 dwellings/HA (for single homes on individual sections)

b) Medium density: 50-100 dwellings/HA (for townhouses and flats)

c) High density: 125-250 dwellings/HA (for an apartment block)

- These only define the typical ranges and are still accompanied by a limit on the typologies included

- No information is provided as to how they arrived at these definitions

Wellington City Council defined medium density as part of the District Plan Johnsonville Medium Density Residential Area Design Guide to aid the industry construction, design and planning of appropriate housing (Wellington City Council, 2013)

a) Medium density: 30-65 dwellings/HA

- Issues of the dwellings/HA include averaging, simplification and ambiguity

- No information is provided as to how they arrived at these definitions or how it is measured (e.g. gross vs net)

BRANZ definition (Allen and Bryson, 2017)

a) Low density: Stand-alone dwellings, generally 1-2 storeys, on an individual section where the size is greater than $400 \mathrm{~m} 2$

b) Medium density: Multi-unit dwellings (up to 6 storeys)

c) High density: apartment buildings greater than 6 storeys, with individual dwelling unit sizes ranging from studio apartments to 3-4-bedroom apartments

- Decided by a nationally based literature review, largely dictated by the Ministry for the Environment definition which was already comprehensive but not used because it contradicts many other MDH definitions in NZ so is unlikely to be accepted nation and industry wide

- Intended to be a definition that is accepted industry wide and is "future proof"

- BRANZ differentiates MDH typologies into 3 main categories:

- 1-2 storey attached houses,

- 2-4 storey attached houses,

- apartments, they completely disregard standalone housing as a possible MDH type (which is what Hobsonville was originally conceived as)

- Context is a huge player in perception of density, however, as BRANZ were looking for a common definition they did not regard this

- BRANZ don't see the information lost in averaging housing or population density across a neighbourhood as a bad thing, acknowledging that different housing typologies deliver different density relationships. They state "a well-designed neighbourhood will incorporate a variety of different house typologies to accommodate the needs of many kinds of people." Which is an optimistic presupposition of what will actually occur within density regulations. 
- Regulatory metrics are often included in definitions and are subject to context and zoning; building height restrictions, site sizes, number of dwellings/HA... ppl/HA min number of dwellings per project, min house size

- They discover that there are two common approaches to defining MDH: typology based, and neighbourhood based

Ghosh and Vale (2009, p519) subcategorise MDH in relation to proximity to city (and height of building); MD mixed nodal (400-800m radius from town centre); 2) MD mixed; 3 ) md residential (Allen and Bryson, 2017)

Ministry for the environment definition (Boffa Miskell Ltd., 2012)

a) "Medium-density housing means comprehensive developments including four or more dwellings with an average density of less than $350 \mathrm{~m} 2$ per unit. It can include stand-alone dwellings, semi-detached (or duplex) dwellings, terraced housing or apartments within a building of four storeys or less. These can be located on either single or aggregated sites, or as part of larger master-planned developments."

- $\quad 350 \mathrm{~m}^{2}$ means plot size, so basically net HHU/HA restriction

- Defined as part of a case study of MDH in New Zealand. They do not outline further how they arrived at this definition

Guy Marriage identified the lack of attention paid to outdoor space in density metrics as a big issue (Moore, 2017). He argues for it to be included in planning and for its relationship with density to be investigated

further.

The results are striking. Usable private open space has gone from an average of 335 square metres before the 1980s to around 93 square metres after 2000. See Table 1 and Figure 1.

\begin{tabular}{|c|c|c|c|c|c|}
\hline \multicolumn{6}{|c|}{ Dimensions of Selected Auckland Examples } \\
\hline & Pt Chevalier & Pt England & Papatoetoe & East Tamaki & Flatbush \\
\hline date of subdivision & 1930s & $1950 \mathrm{~s}$ & 1970s & $2000 s$ & 2015 \\
\hline distance from city centre $(\mathrm{km})$ & 5.9 & 9.2 & 15.7 & 16.3 & 19.6 \\
\hline net density & 14.7 & 14.8 & 12.4 & 23.6 & 23.8 \\
\hline front to front distance $(\mathrm{m})$ & 34.5 & 41 & 33.8 & 23.7 & 23.6 \\
\hline average lot area $(\mathrm{m} 2)$ & 682.4 & 676.0 & 803.8 & 424.5 & 420.2 \\
\hline net average dwelling footprint & 117.2 & 110.9 & 191.0 & 180.8 & 205.7 \\
\hline average lot coverage & $17 \%$ & $16 \%$ & $24 \%$ & $43 \%$ & $49 \%$ \\
\hline average back yard (m2) & 319.3 & 342.7 & 343.1 & 99.1 & 86.5 \\
\hline average front yard (to curb) (m2) & 108.3 & 143.4 & 215.0 & 94.5 & 83.6 \\
\hline back to back distance $(\mathrm{m})$ & 46.6 & 43.7 & 31.2 & 9.8 & 8.9 \\
\hline
\end{tabular}

\section{REGULATING DENSITY}

Current regulations aim to encourage densification:

Planning regs (until 2015) encourage detached houses on standalone plots (Moore, 2017, p. 74)

1. Minimum area per person / HHU - 1 person per 8sqm or $1 \mathrm{HH}$ per 400sqm 
2. Maximum site coverage ratio - $35-40 \%$ building coverage

3. Minimum front, rear and side yards - $1 \mathrm{~m}$ side and rear, 2.5-3m front

4. Recession plane on site boundary - between 2-3m vertically with an angle of 35-55 degrees

5. Minimum private open space (area + shape) - between 80-100sqm, minimum width of $4 \mathrm{~m}$

P4 2016 changes - encourage infill housing (Moore, 2017, p. 74)

1. Minimum area per person / HHU - second dwelling can be added to site as long as approx. $5 s q m, 1.8 m$ deep outside area per extra person provided

2. Minimum private open space (area + shape) - 20sqm, minimum width $4 m$ to allow 'outlook space'

Many developments (in the report that Boffa Miskell developed about medium density housing) have a recorded plan change to allow the development, as well as many simply fitting in with pre-existing plan. (Boffa Miskell Ltd., 2009)

WCC district plan: site coverage is the key mechanism used to manage the density of new development. (building recessions and heights also predominant)

Currently discouraging the fragmentation of land parcels within the MD residential areas (inhibits comprehensive redevelopment)

Recent residential development (in the last ten years) has comprised significant apartment development in the CBD, low density greenfield development in northern suburbs (particularly Churton Park, Woodridge and Johnsonville West), and incremental backyard infill throughout the City (Mead, 2007)

RMA - New Zealand Regulatory case studies. (Mead, 2007) Approaches of control through planning include:

- Zoning

- Some plans create specific high density zones

- others (like Waitakere and Manukau) used a form of overlay

- Wellington City's approach of a Restricted Discretionary Activity status is very liberal

- Site area / density (controlling open space, building bulk and mass)

- ONLY some plans use density or site area controls

$\circ$ Minimum site area controls are generally in place to ensure that a comprehensive approach to development occurs (with more possible design benefits due to flexibility, in theory).

- Issues with development costs for site amalgamation

- less building typologies (institutional feel)

- No minimum road frontage

- SOME plans also have density max as number of units per land area / site

- Other plans use standards of building coverage, on-site open space and landscaping to control building bulk and mass

- Only ONE plan uses a floor to area ratio control, advantageous by directly controlling building mass with flexibility in unit number and type 
A useful standard adopted through a recent plan change in the Wellington Central Area is that of "massing". This approach regards a site as a three dimensional envelope defined by the site boundaries and maximum building height. (Mead, 2007)

\section{DENSITY HISTORY}

In-depth research on the history of density within New Zealand is outside the scope of this research as the focus is on the quantification methods and metrics. It is only investigated enough to inform the case studies chosen later in this report. Further research on this topic will be vital for continuing the development of a density analysis method.

- This is very large research gap that is crucial to understanding New Zealand's specific density

- The move to intensification and diversified densities is only recent (previously the low density, quarter acre, standalone house as per 60s post war was the prevailing model) (Allen and Bryson, 2017)

- The growth of MDH has largely taken place since 1971 (Davey, 1978)

- Wellington City Council is currently employing the growth spine concept for urban growth, residential intensification along transportation nodes. (Gray, 2007)

The growth context of MDH (Notes below are from Allen and Brysons MDH report for BRANZ)

\section{Until 1960s}

- Predominantly low-density urban form following quarter-acre section model

- Med-density typologies predominantly 1 storey and sometimes 2 storey 'brick and tile' flats. 3-6 homes connected on one quarter-acre block.

- Larger centres - apartment developments in town centres and downtown areas but rarely above 3 storeys

- Suburban sprawl was being encouraged by government policies. Population (in relation to available land) was $v$ low

\section{Since 1960s}

- Growth pressures increased in main centres, intensification significantly shaped city urban forms, levels of growth and growth patterns different between diff areas

- Auckland growth semi contained by "rural urban boundary/metropolitan urban limit/fence" to protect rural/open land and high environmental amenity and encourage intensified development

- Wellington growth considerable intensification through suburban infill and downtown apartment development (central city). Broader metropolitan area low density due to continued availability of greenfield land (unlike the geographical constraints of the city)

- Predominantly single-storey detached housing continues

Today

- A compact city approach to urban growth

- NZs changing demographic profile and lifestyles - following overseas trends (density sustainability, quality of life)

- "Growth MGMT strategies in NZ are underpinned by a belief that distributing density within existing neighbourhoods is the most effective way to manage growth without sprawling or compromising quality of life"

- Supply of Larger dwellings continued to increase in recent years, particularly at city fringes 
- Larger dwellings have also become occupied by smaller households - surplus bedrooms are increasing

- Smaller dwellings have increasingly become occupied by larger households ( 1 and 2 bedrooms)

\section{SUMMARY OF RESEARCH GAPS}

- Need to be better at defining and clarifying for communication

- "Real-world complexity and the interrelationships between variables and factors must be addressed in research on density as it is in practice. Real-world complexity includes a subjective element that is always present in people's behaviours, expectations, and attitudes (including those of decision-makers, planning professionals, and researchers)" (Churchman, 1999, p. 407)

- Cannot make value judgements on what the best metrics are at this stage, as it is dependent on the result desired

- "no one solution will meet the needs of every situation, context, person, or group" (Churchman, 1999, p. 407)

- Interrelations are crucial and cannot be simply ignored or simplified, but also cannot be nailed down (Dovey and Pafka, 2014)

- "much more research is needed on the various aspects and ramifications of different kinds and levels of density" (Churchman, 1999, p. 407) especially objective and perceived!!

- Representation of density distribution for example typology diversity, range of housing sizes and distribution of housing over an area all need further investigation and have barely been researched!

\section{CASE STUDY ANALYSIS}

At this stage this case study analysis is limited to smaller developments. The aim is to see what needs to be measured and which parameters affect the character of medium density housing. Initially, case studies were selected that have all been described as medium density housing in the literature. The aim was to have a mix of public and private examples from the 1970 s and the early $21^{\text {st }}$ century in both Auckland and Wellington. The purpose was to select at least two case studies for detailed analysis to use as a pilot study of density measurement techniques in the New Zealand context. The references for each scheme are given where the schemes are introduced.

\section{SELECTED CASE STUDIES}

Six appropriate case studies were selected from the larger list. Of these, three were from the $1970 \mathrm{~s}$ and three were from the early $21^{\text {st }}$ century. These date ranges were chosen to provide a reasonable cross-section of medium density housing in New Zealand over time. Medium density housing only emerges as its own housing typology in New Zealand literature in the 1970s. It was preceded by the provision of either sprawling, suburban typologies or flats and apartments that were considered as high density.

\section{MDH DEFINITIONS EMPLOYED}

A qualitative definition from 1978 applies to the Arlington, Taylors Road and Habitat housing development case studies. They were found through Te Waharoa (Victoria University library website) 
and the report "Medium Density Housing and its place in the urban environment" by Judith A. Davey $(1978$, p. 10) for the Urban Affairs Committee Environmental Council. The definition employed is:

"Housing which lies between the single family house on its own section (say down to onefifth acre or 800sqm) and multi-storey apartments over three floors high"

For the case studies constructed within the last decade (2008-2018) there are several definitions that apply, all of which are principally qualitative definitions. These case studies are Regent Park, 55 Duke Street and Zavos corner, found through www.MDH.org (a BRANZ website) and the Wellington City Council website. Most schemes appeared on both websites as exemplars of medium density housing. The definitions applied are:

- "Medium-density housing can be stand-alone, semi-detached, terraced houses or apartment buildings, all up to three storeys high" ("About medium-density housing," n.d.)

- BRANZ: “Multi-unit dwellings (up to 6 storeys)" (Allen and Bryson, 2017, p. 12)

For this pilot study, only the Taylors Road development from 1975 and the 55 Duke Street development from 2011 were analysed. This provides a test of the result of varying parameters and measurements when analysing density. 


\section{ANALYSIS PLAN 1:1000}

$\stackrel{N}{\oplus}$

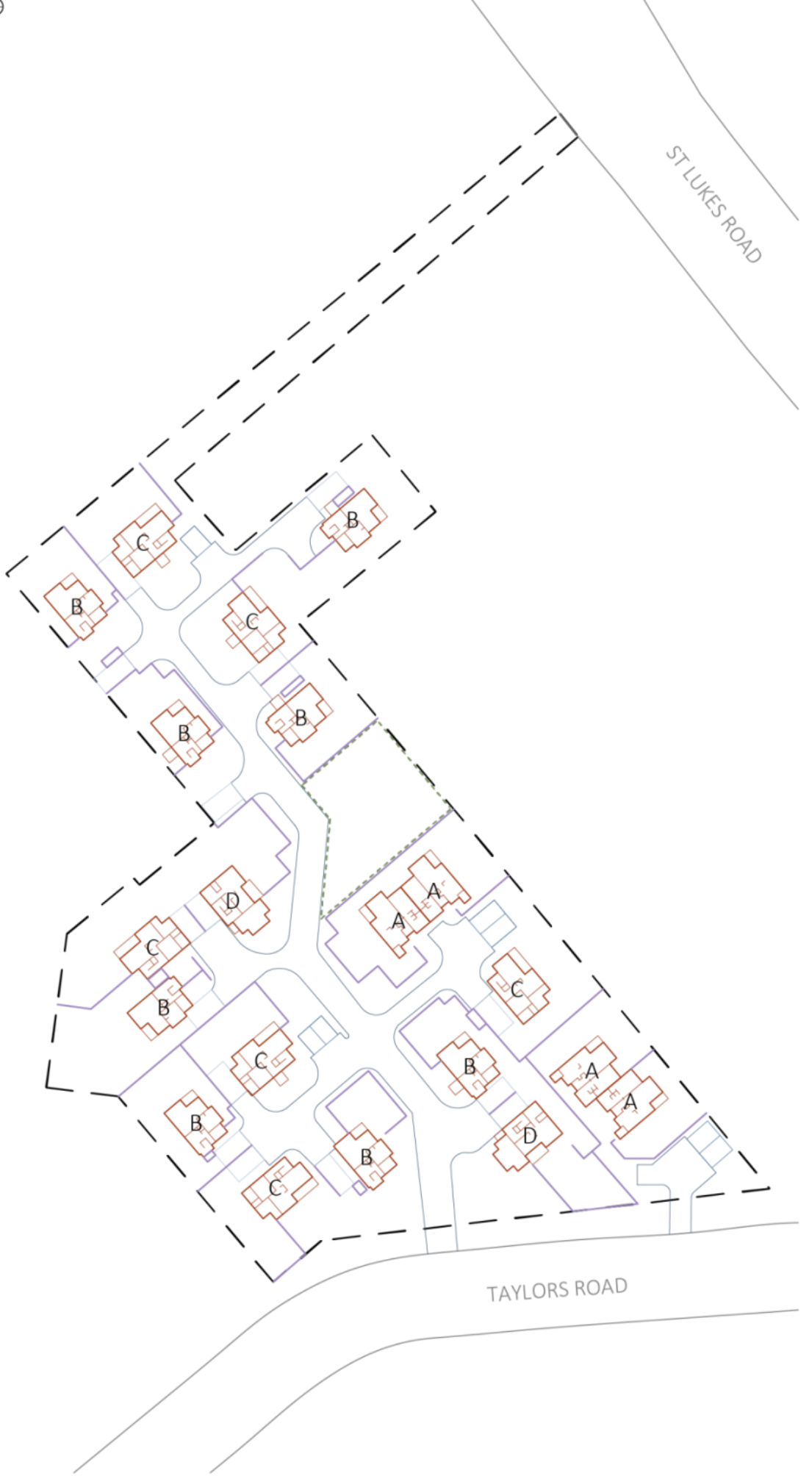

ANALYSIS PLAN KEY

- - Site boundary

External road edge

Internal/shared road edge

Car port

Car park

Designated communal space

Screening fence (divides private space)

External building wall

Internal building wall or building footprint edge without wall

Bedrooms

\section{HOUSE FLOOR PLANS 1:1000}

Ground floor First floor

A

1 double

bedroom

B

2 double

bedrooms

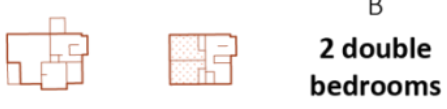

2 double +

1 single

bedrooms
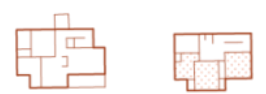

D

3 double bedrooms 


\section{Taylors Road}

Designed by Housing New Zealand Corporation in 1975 with an aim to provide family accommodation, reasonably close to central Auckland. (Davey, 1978, p. 33)

\begin{tabular}{|l|l|}
\hline Population in 1978 (Davey, 1978, p. 7) & 55 \\
\hline Population now (D Badman 2018, personal communication, 2019) & 51 \\
\hline Occupancy rate (Davey, 1978, p. 7) & 2.1 \\
\hline People per hectare (Davey, 1978, p. 7) & 76 \\
\hline Dwellings (Davey, 1978, p. 7) & 20 \\
\hline Area (Hectares) (Davey, 1978, p. 7) & 0.76 \\
\hline
\end{tabular}

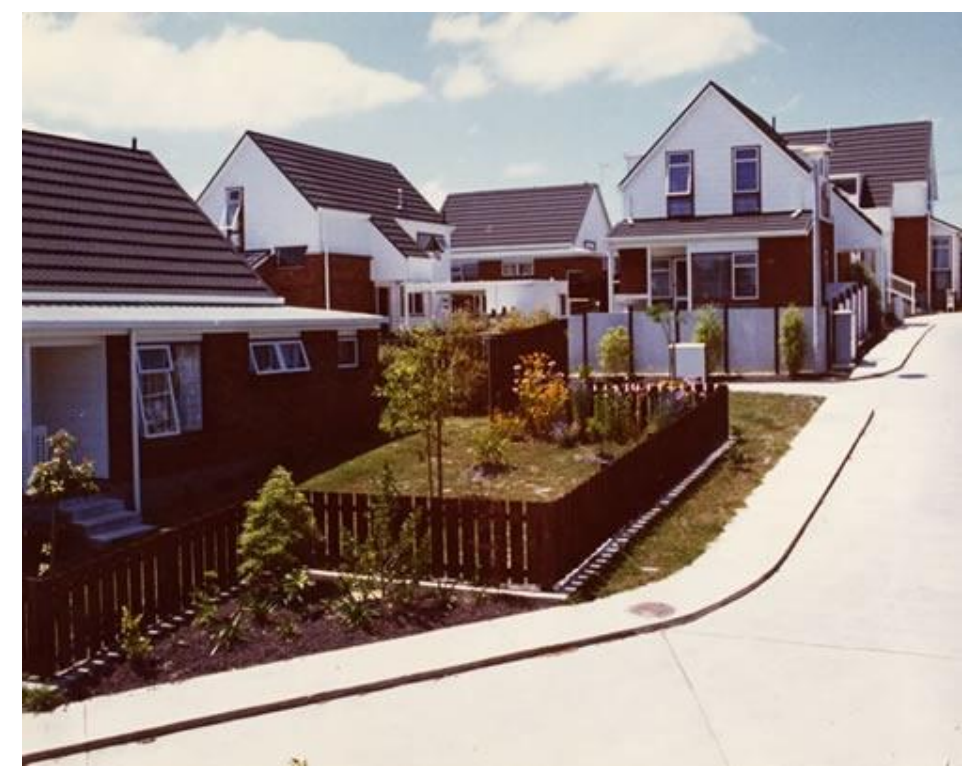

Figure X: Taylors Road housing (Housing New Zealand Corporation, 2014)

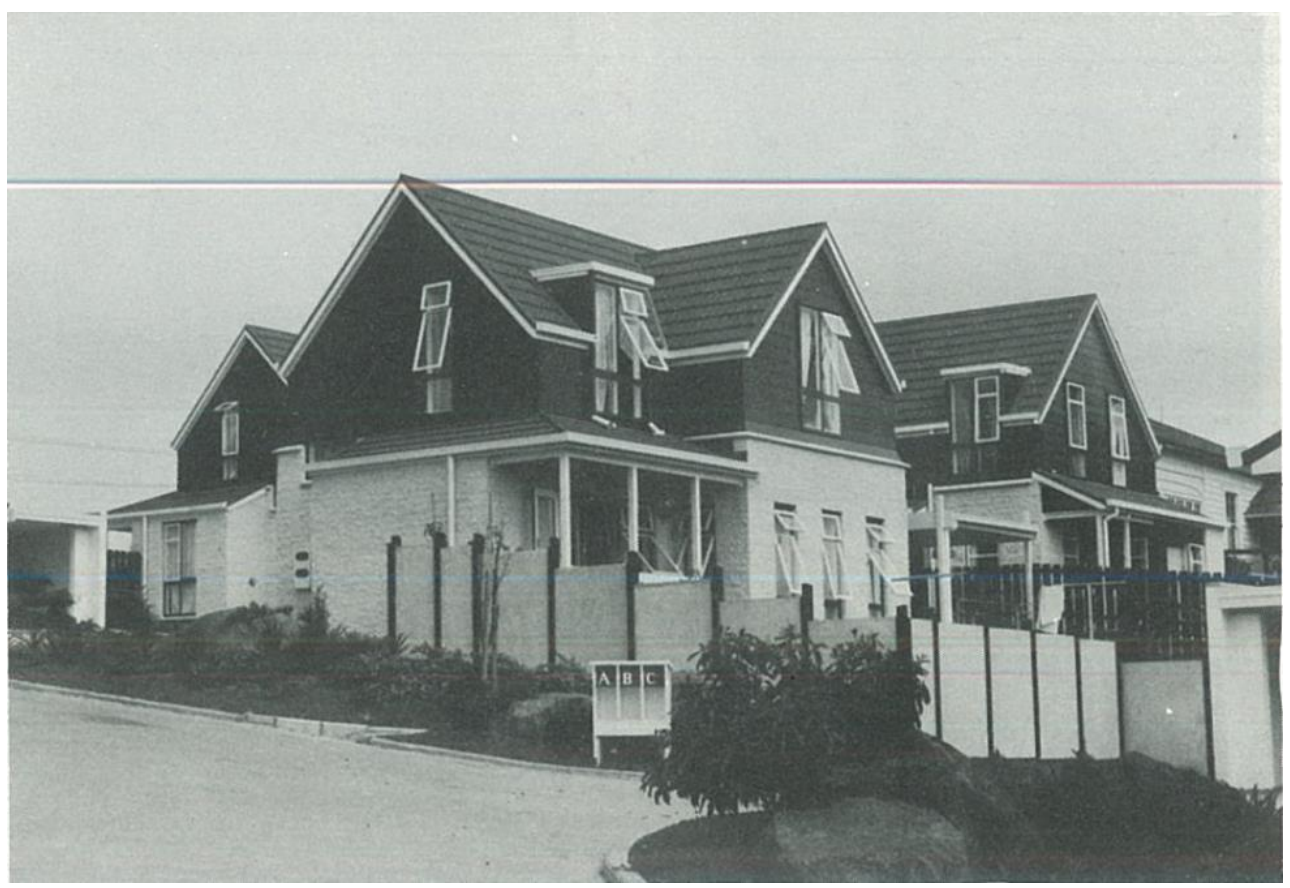


Figure X: Taylors Road housing in 1978 (Davey, 1978, p. 33)

\section{DUKE STREET OVERVIEW}

ANALYSIS PLAN 1:1000

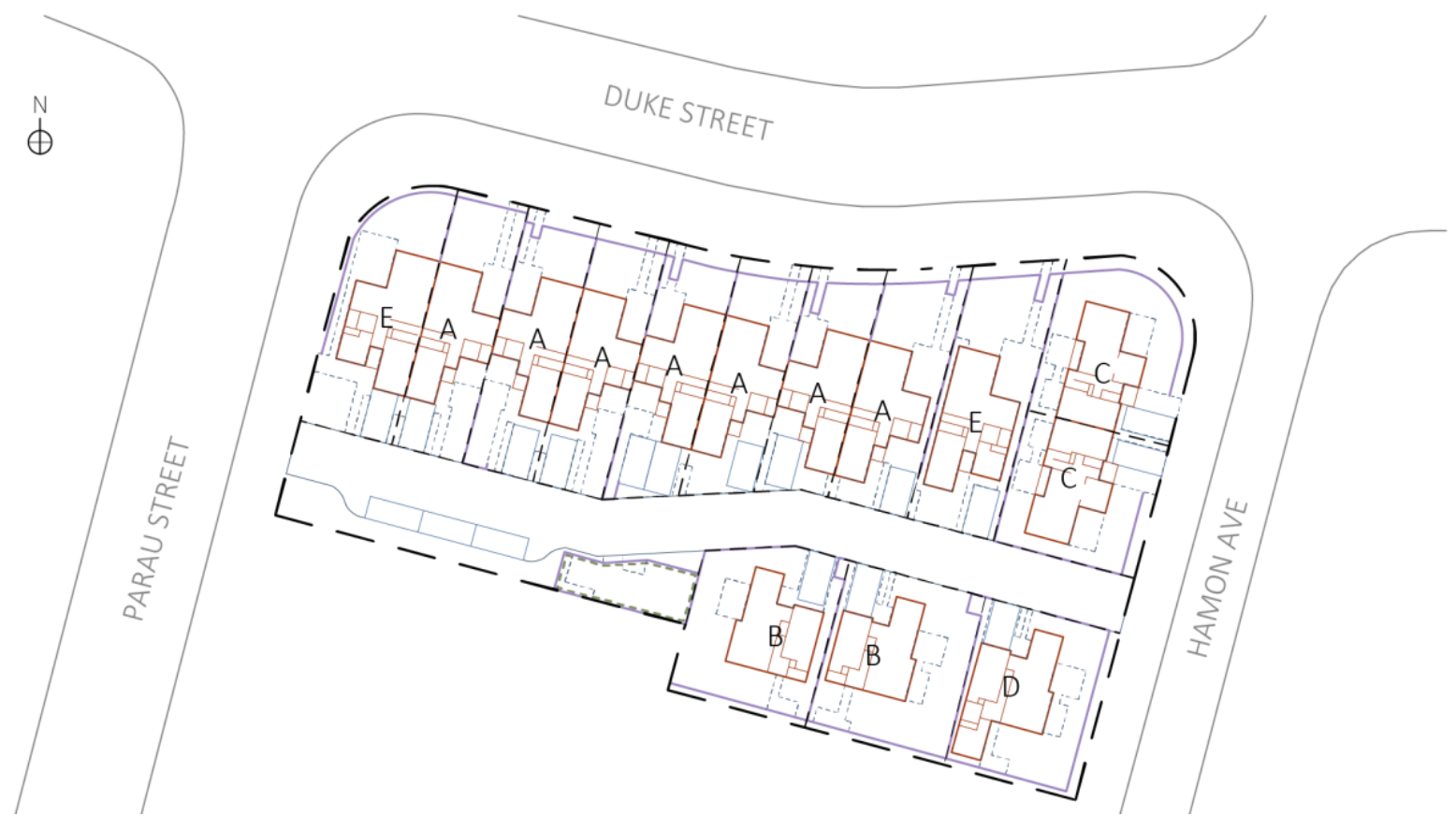

\section{Duke Street}

Designed by Housing New Zealand Corporation in 2011 as a redevelopment with an aim to provide family accommodation, in a high demand area in Auckland. (Davey, 1978, p. 33)

\begin{tabular}{|l|l|}
\hline Population now (D Badman 2018, personal communication, 2019) & 36 \\
\hline Dwellings (Davey, 1978, p. 7) & 14 \\
\hline Dwellings per hectare (Auckland Design Manual, n.d.) & 31 \\
\hline Area (Hectares) (Auckland Design Manual, n.d.) & 0.45 \\
\hline
\end{tabular}
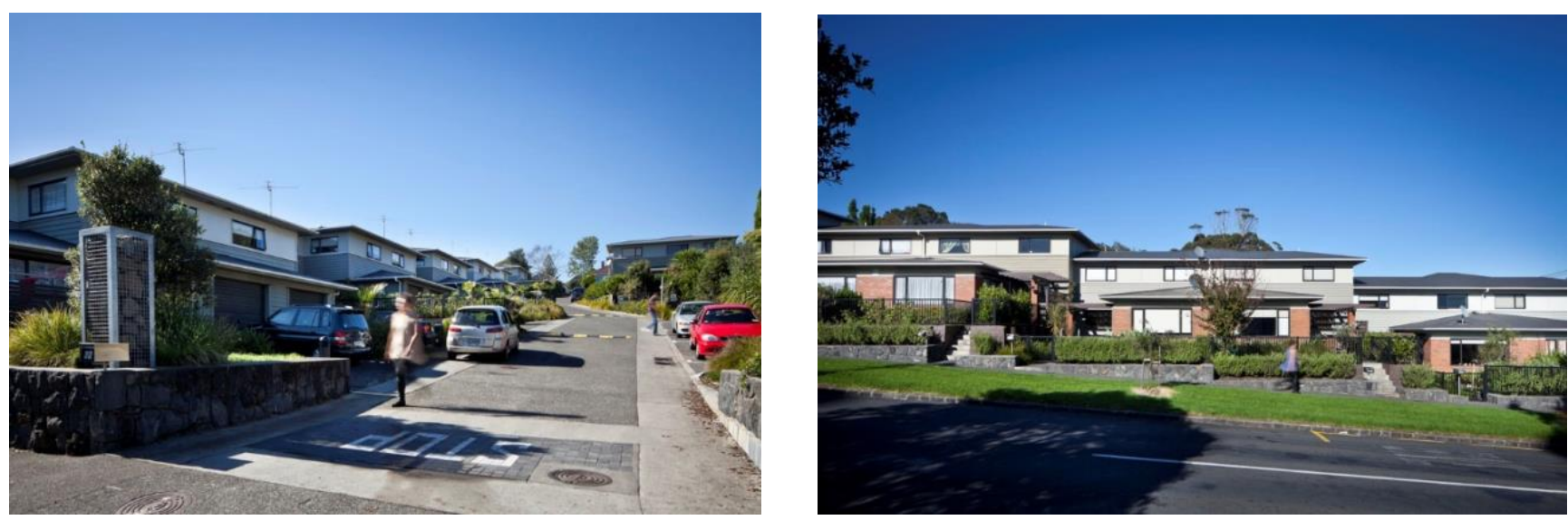

Figures $X$ and $X$ : The 55 Duke Street housing development (Auckland Design Manual, n.d.) 


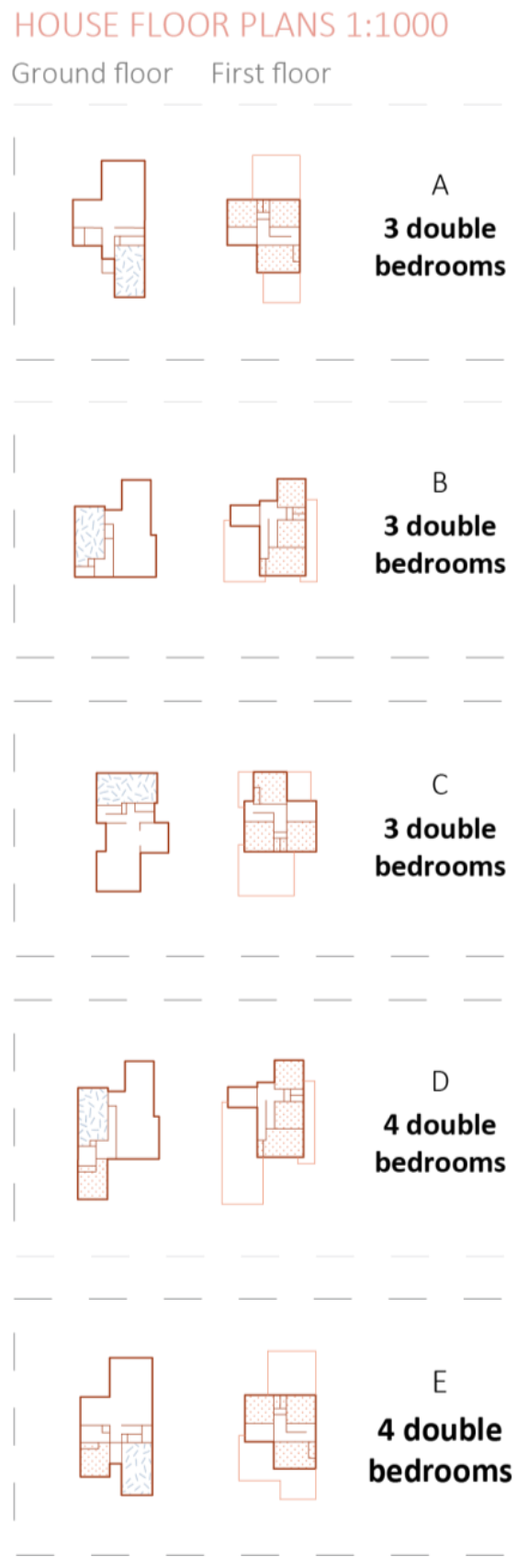

\section{ANALYSIS PLAN KEY}

- - Development site boundary

- - - Individual legal lot boundaries

External road edge

Internal/shared road edge

Paving edge

Car park

- Designated communal space

Screening fence (divides private space)

External building wall

Internal building wall or building footprint edge without wall

Roof/building edge below

Bedroom

Garage 


\section{ANALYSIS METHOD}

The analysis process was largely informed by Dovey and Pafka (2014) and Pont and Haupt (2010).

- Dovey and Pafka: three fields of density measures - buildings, populations, space and the importance of defined and varying territory and scale

- Pont and Haupt: territory and scale, understanding of ratios between space types

- Apply all possible and appropriate measurements and metrics, including over different scales and territories.

- $\quad$ NOT making a value judgement on which density measurements are better at this point

- Interested in the distribution of space

- $\quad$ How do the numbers differ depending on the assumptions we are making

- How many different ways can we find to measure density (what does medium density actually become)

- To help forecast and control what we want density actually to do, shrinking car space rather than communal etc.

- Sociocultural context of communal space ? e.g. clotheslines etc.

Key to this method of density analysis is the use of detailed site and floor plans related to census mesh block data from Statistics New Zealand (2013) and doctoral research that examined household sizes and types (Bakshi, 2017). From these, totals of area types (both as area measures and counted totals) and estimates of populations can be derived and examined in the various ways of calculating density.

\section{TERRITORY DEFINITIONS AND DISTRIBUTIONS}

Measurement territories must be carefully and precisely defined to minimize ambiguity and inaccuracy of measurements. The territories used in this density analysis exploration are largely informed by Dovey and Pafka (2014), and Pont and Haupt (2010). For this analysis, territories are more diverse and precise then for typical density analysis. Each of the following sections provides a set of territory definitions used, then explores the provision of respective territories within the case studies. As the case studies are different scales, several different comparative techniques are used. These question and critique the simplicity of existing density definitions and analysis methods whilst beginning to explore the possible basis of a re-definition of New Zealand housing density.

\section{DEFINING USABLE SPACE MINIMUMS}

The contrast between provided land area compared to what is actually practical for use quickly became a prominent issue. Therefore, a brief survey was made of the literature to help define what is considered as usable and developable space. It was difficult to pin down an exact definition as most literature was concerned with opinions, the necessity for open space for health reasons, ecological issues, developable or usable internal (rather than open) space, or the change of space use and size over time, especially for private open space. The measurements from council district plans were not used as there was no explanation of what the measurements were based on and whether they provide appropriate, usable space sizes. The main statements off which size judgements were based are listed below:

- AMCORD minimum provision recommendation: "As explained by Figure 5, a narrow strip around a house can amount to 34-48 per cent of the lot. The provisions therefore included an additional minimum dimension for a useful backyard, the principal area of $25 \mathrm{~m}^{2}$. The minimum linear dimensions were $4 \mathrm{~m} \times 4$ m." (Hall, 1987, p. 428) 
- The Auckland design manual (Auckland Council, n.d.) recommends that the depth of the private open space to the number of storeys of the terraced house should correspond but it does not provide any measurements. Focus was on the location and qualities of the space.

- Hall $(2008$, p. 37) studied the changes in Australian backyards, focusing on the Queensland region and argues for backyard sizes that accommodates "...space for the following activities: sitting out in private, secure outdoor children's play, provision for swimming, barbeques, drying laundry and other components of a sustainable lifestyle." Although swimming is less essential in the cooler climate of New Zealand, the rest of the activities are still relevant to local residents needs.

- Moore (2017, p. 8) did a similar study in Auckland and argues for a $12 \mathrm{~m}$ deep backyard, which is possible while maintaining density by removing the side setbacks, minimising the front setback, and limiting the interior living space depth.

- The New Zealand Ministry for the Environment (2012, p. 12) describes good outdoor living space provision as that which includes enough space to fit a table and chairs (as a minimum) comfortably, shelter from adverse winds, and sunlight throughout most of the year and most of the day.

Little has been written about the size and quality of shared space within housing developments. The following is from the Auckland design manual:

- "...size the outdoor spaces relative to the number of residents; making sure the space is appropriately landscaped and contains the appropriate facilities - e.g. trees for shade in summer" (Auckland Council, n.d.)

\section{DEVELOPMENT WIDE TERRITORIES}

- Total land area that which is within the defined legal site boundaries of the development;

- Total developable area is defined as "land that is suitable as a location for structures and that can be developed free of significant impact on natural resource areas." This follows the definition of The Institute for Local Governments (2010, p. 18). This is the measure of land that was able to be built on;

- Total open space is the total building footprint area subtracted from the 'total developable land area';

- Total built space is the total area of building footprints;

- Total car-centric space is defined as the total space designated for motor activities within the development, including garages, parks, car ports, turning ports and roads;

- Total parking space is defined as the total land area dedicated to car parks including garages. At this stage of the analysis, it is assumed that this is the only space that will be used for parking and that it is used exclusively so;

- Total land degraded is a measure of all impervious surface area in the development including building footprint area and any paved or sealed area; 


\section{Figure X: Larger territory distributions}

TAYLORS ROAD

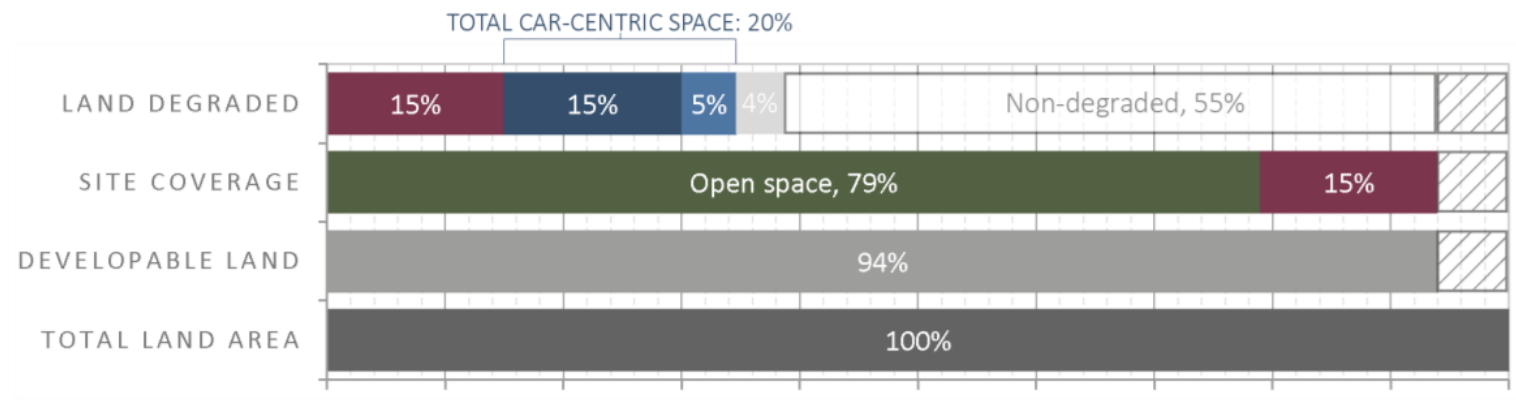

55 DUKE STREET

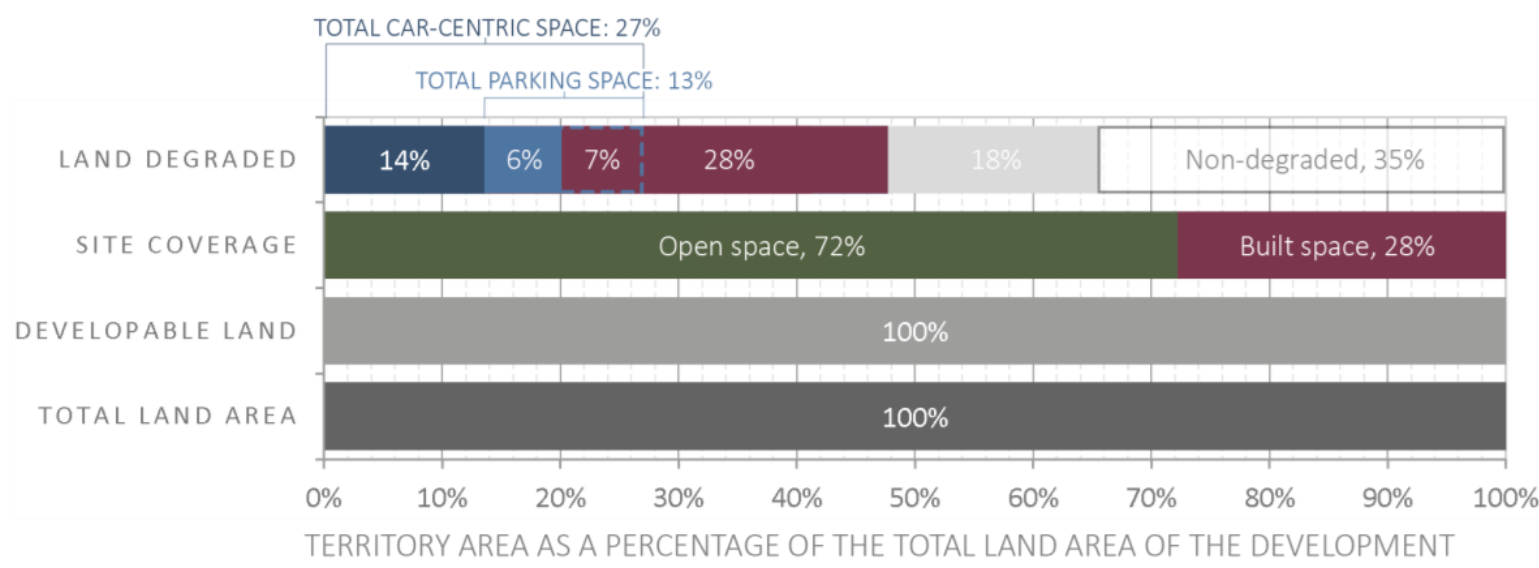

KEY

\begin{tabular}{l} 
Total land area \\
Total developable area \\
Total open space \\
Total built space \\
Total parking space (excl. garages) \\
Shared road space \\
\hline- Un-buildable space \\
Non-degraded land \\
Other impervious surfaces area
\end{tabular}

The proportions of spaces are compared between developments to provide an understanding of space distribution without the complication of their varying scales. The territories discussed in this section are discussed in further detail later in this report. Both of these developments are considered to be medium density housing, however it is already obvious how much they differ. The proportion of built space within the 55 Duke Street development almost doubles that of Taylors Road. This indicates that Taylors Road is more spacious and less intense, therefore it is likely thought of as a much lower density by its residents compared to 55 Duke Street.

The proportion of open space is similar, however the Taylors Road project is abundant in green open space when the developments are compared. This means that Taylors Road is much more resilient. Yet, the percentage of open car-centric space is relatively similar, showing that this change is related to landscape design, increased built space and provision of indoor parking. The latter two factors are 
intrinsically linked, but the addition of garages alone does not explain the increase in building footprint.

\section{Figure X: Larger territories per person}

COMPARISON OF OCCUPANCY RATES OF TERRITORIES

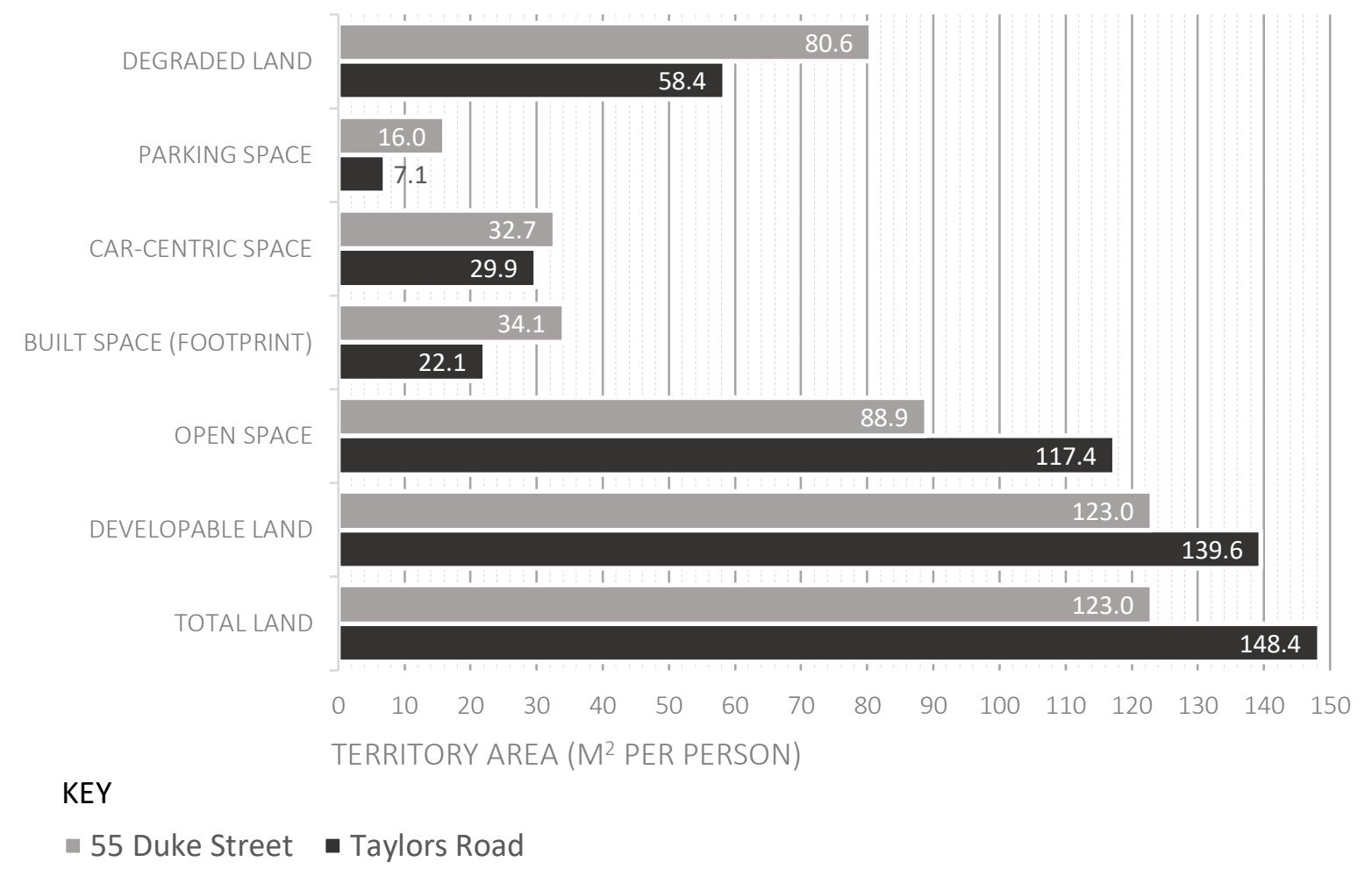

Translating these territories to occupancy rate measures allows the space use to be related to the residents perception of provided space. It gives a meters squared value of space per person, communicating the level of compaction of the residents (i.e. how close together they are living). 55 Duke Street has less land available per resident, so a higher level of population density and compaction. However, it also has much more built space per resident, demonstrating that although overall living is more compact, interior living specifically is still less compact. There is also over double the amount of parking space per person in 55 Duke Street than in Taylors Road.

\section{SHARED SPACE TERRITORIES}

- Shared space is defined by legal site boundaries when applicable, otherwise as defined by everything outside of the 'perceived private area' (defined below). This will provide a measure of the shared dead space when it is compared with 'developable shared space';

- Developable shared space is defined as 'shared space' as above, excluding any areas which would become dead space due to steepness or narrowness (of a diameter less than $3 \mathrm{~m}$ ). The diameter measurement is based on a minimum size of area useful for outdoor recreational activities or suitable for built structures;

- Usable shared space is defined as 'shared space' as above, but excluding car-centric space and any areas which would become dead space due to steepness or narrowness (of a diameter less than $3 \mathrm{~m}$ ). This gives a measure of the shared space that is people oriented and able to be used recreationally by the residents of the development; 
- Community space is defined as the allocated space for shared activities and amenities;

- Open community space is defined as 'community space' as above, but excluding any interior space to provide a measure of outdoor space to be used recreationally by the residents of the development;

- Shared car-centric space is defined as 'total car-centric space' but excluding any private spaces such as garages, carports and driveways and carparks designated to specific properties;

- Shared parking space is defined as the shared land area dedicated to car parks;

- Shared road space is defined as the total space dedicated to shared roads within the development area including joint-access lanes and semi-private roads;

\section{Figure X: Shared territory distributions}

TAYLORS ROAD

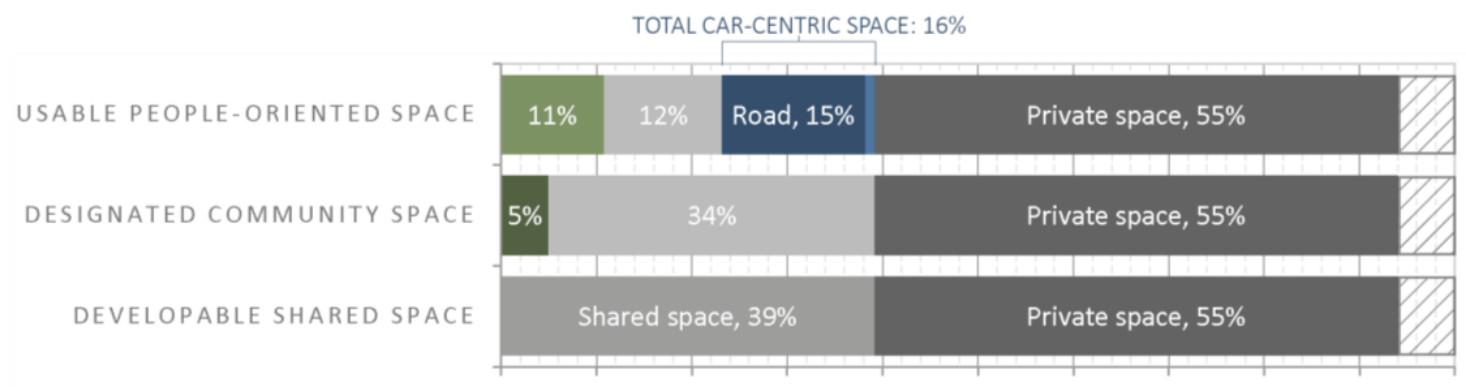

55 DUKE STREET

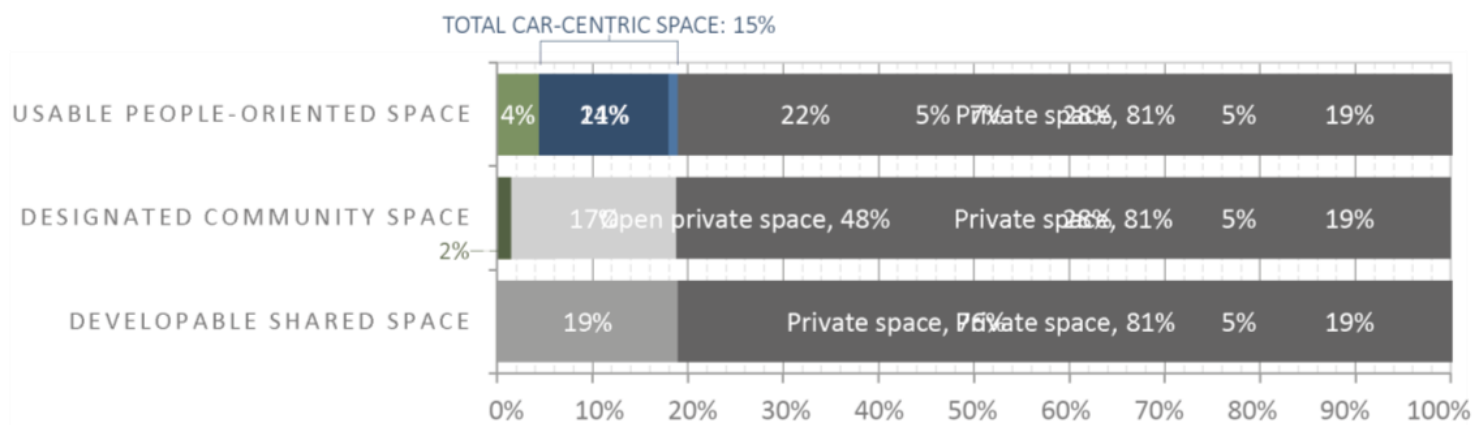

TERRITORY AREA AS A PERCENTAGE OF THE TOTAL LAND AREA OF THE DEVELOPMENT

KEY

Private space

Developable shared space

Other shared space

Open community space (these developments don't have any built community space)

Usable shared space

Shared Parking

Shared road space

Un-buildable space 
Figure X: Shared territories per person

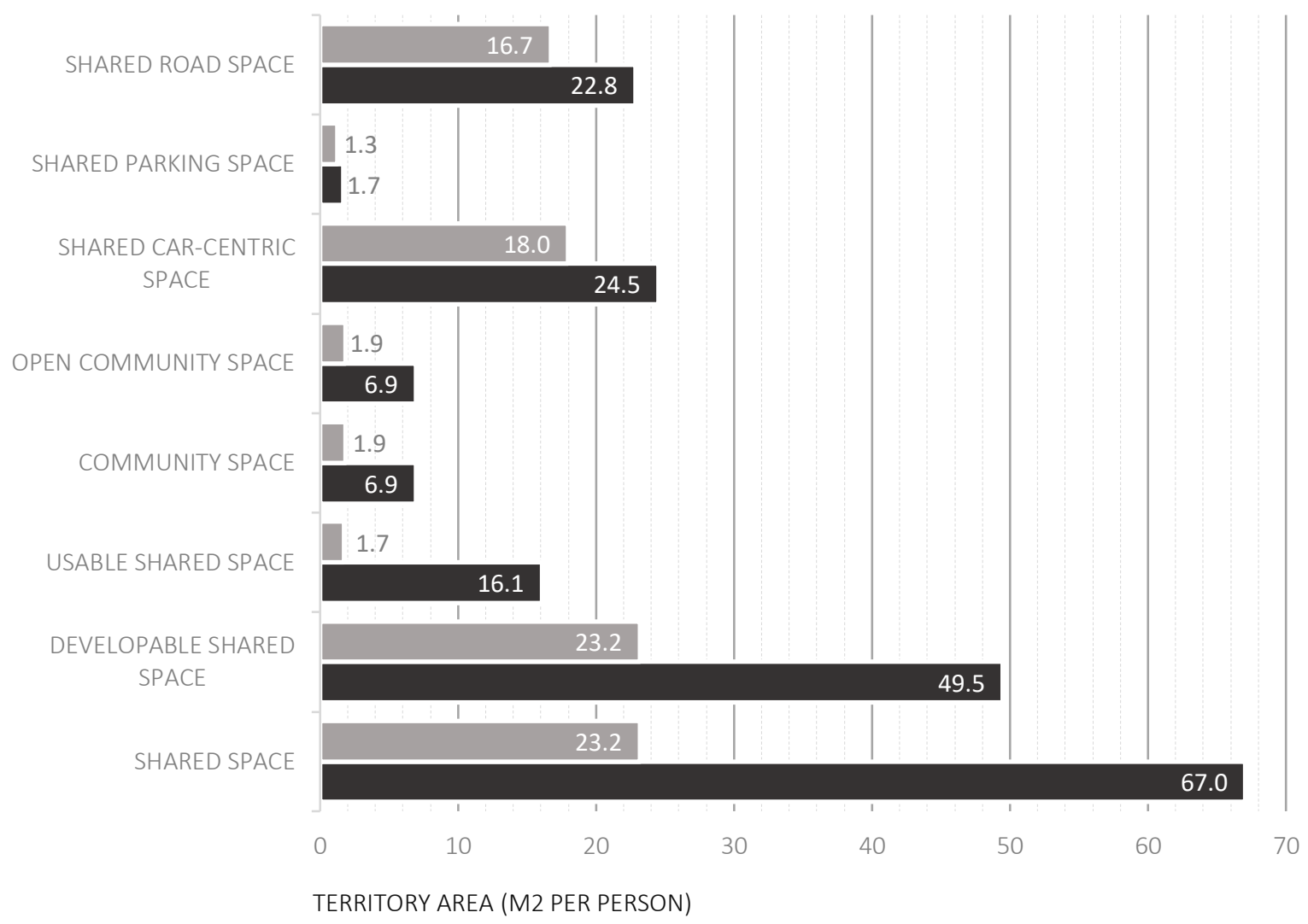

KEY

- 55 Duke Street - Taylors Road

\section{PRIVATE SPACE TERRITORIES}

- Allocated private area is defined by legal site boundaries. This can only apply to sites that have been subdivided;

- Perceived private area is defined by physical boundary lines (e.g. fences) that visually separate the space adjacent to a house from its surroundings;

- Private open area is the 'building footprint area' subtracted from the 'allocated private area' when available, otherwise subtracted from the 'perceived private area';

- Usable private open area is the area available for outdoor living and recreation. It is 'perceived private area', excluding the 'building footprint', any car-centric space (e.g. parking) and areas which would become dead space due to excessive steepness or narrowness (such as skinny side setbacks between houses or areas that can only be used for access). However, it does include spaces such as porches and balconies, as long as they are large enough to accommodate a seating area comfortably. This is an important differentiation from total private open area which includes an aggregation of dead areas and parking;

- Garage space is defined as the total floor area of garages within the development. At this stage of the analysis, garages are assumed to be used as car spaces rather than for storage or other uses such as a gym or play space; 
- Private parking space is defined as the private land area dedicated to car parks including garages;

- Private built space is the total area of building footprints dedicated to private use;

- Private interior floor space is the total floor area of private buildings within the development, measured within the building walls and including space such as storage, service areas and hallways;

- Private storage space is the total floor area dedicated to storage including wardrobes, cupboards and pantries;

- Bedroom space is the total floor area designated to be inhabited as bedrooms, including ensuites and spaces such as wardrobes;

\section{Figure X: Private territory distributions}

TAYLORS ROAD

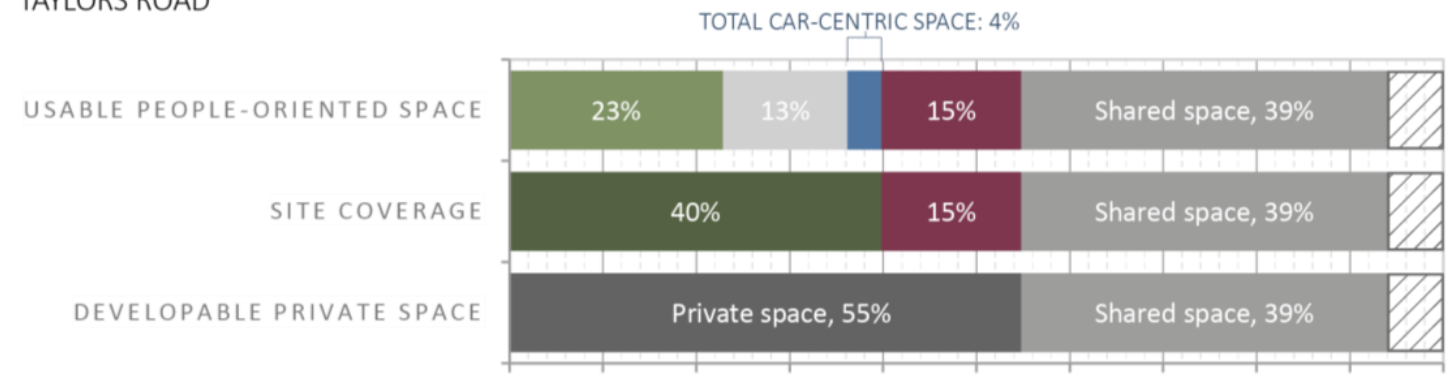

\section{DUKE STREET}

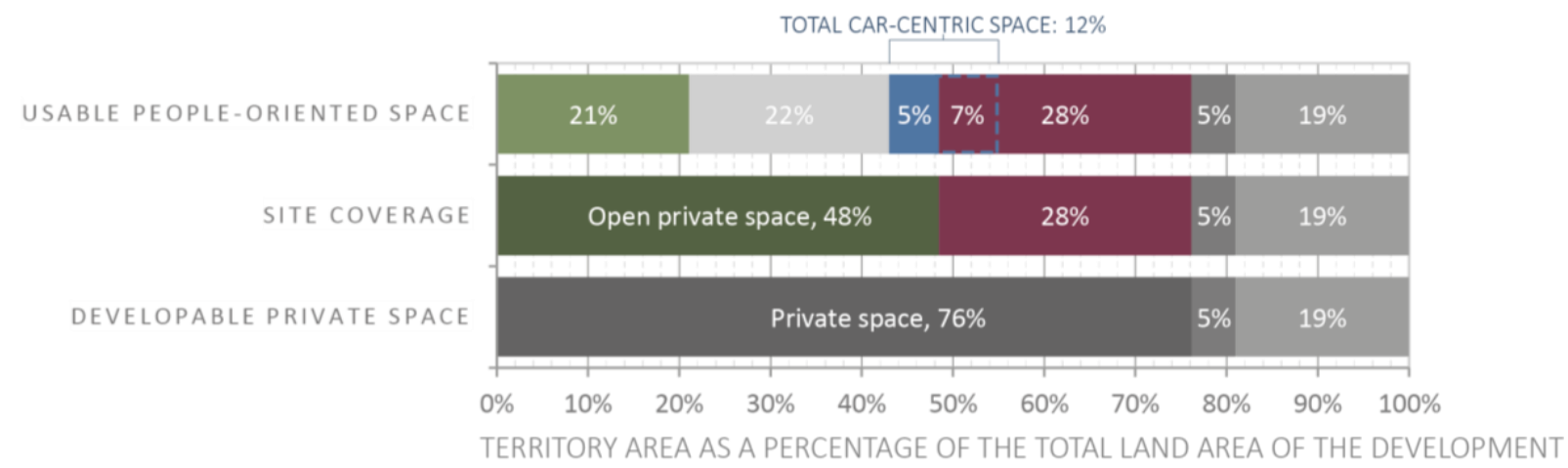

KEY

Perceived private space

Remaining private allocated space (dead space within the legal boundaries but outside of private fences)

Shared space

Other private space

Open private space

Usable private open space

Private outdoor parking

Built space

Un-buildable space

---J Built parking space (garages)

\section{Figure X: Private interior territory distributions}

AREAS AS A PERCENTAGE OF THE WHOLE SITE 


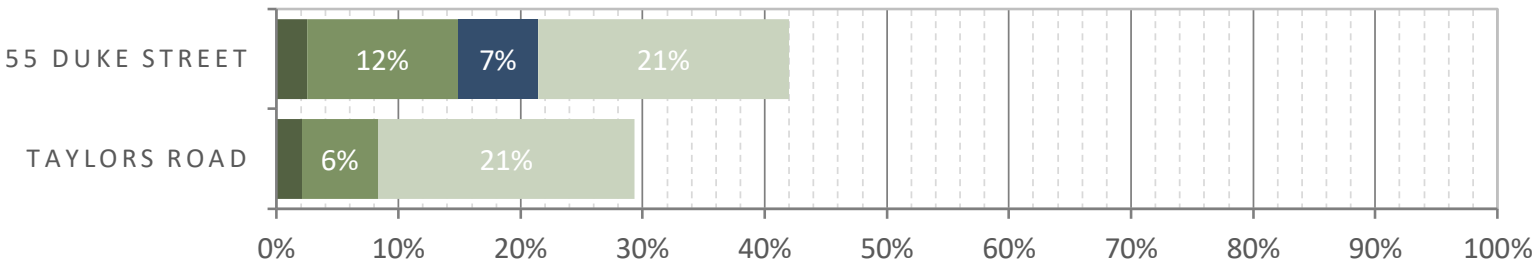

AREAS AS A PERCENTAGE OF THE TOTAL FLOOR AREA

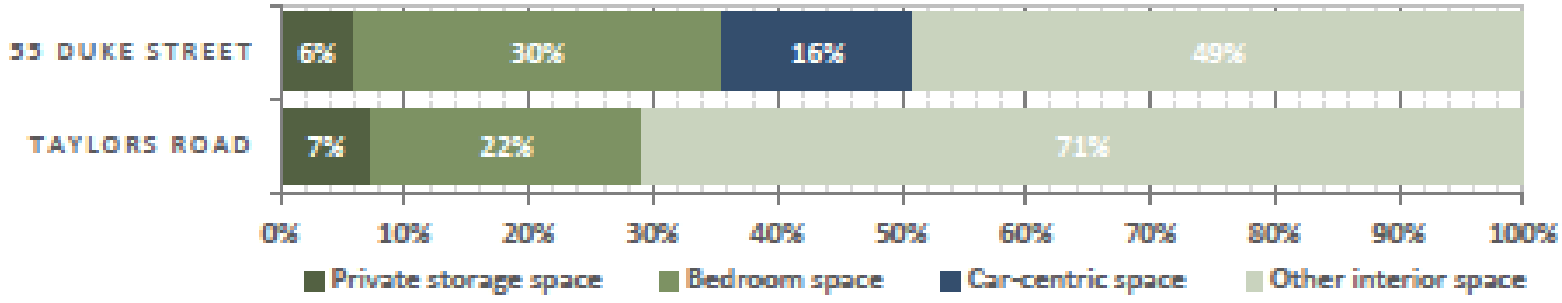

\section{Figure X: Private territories per person}

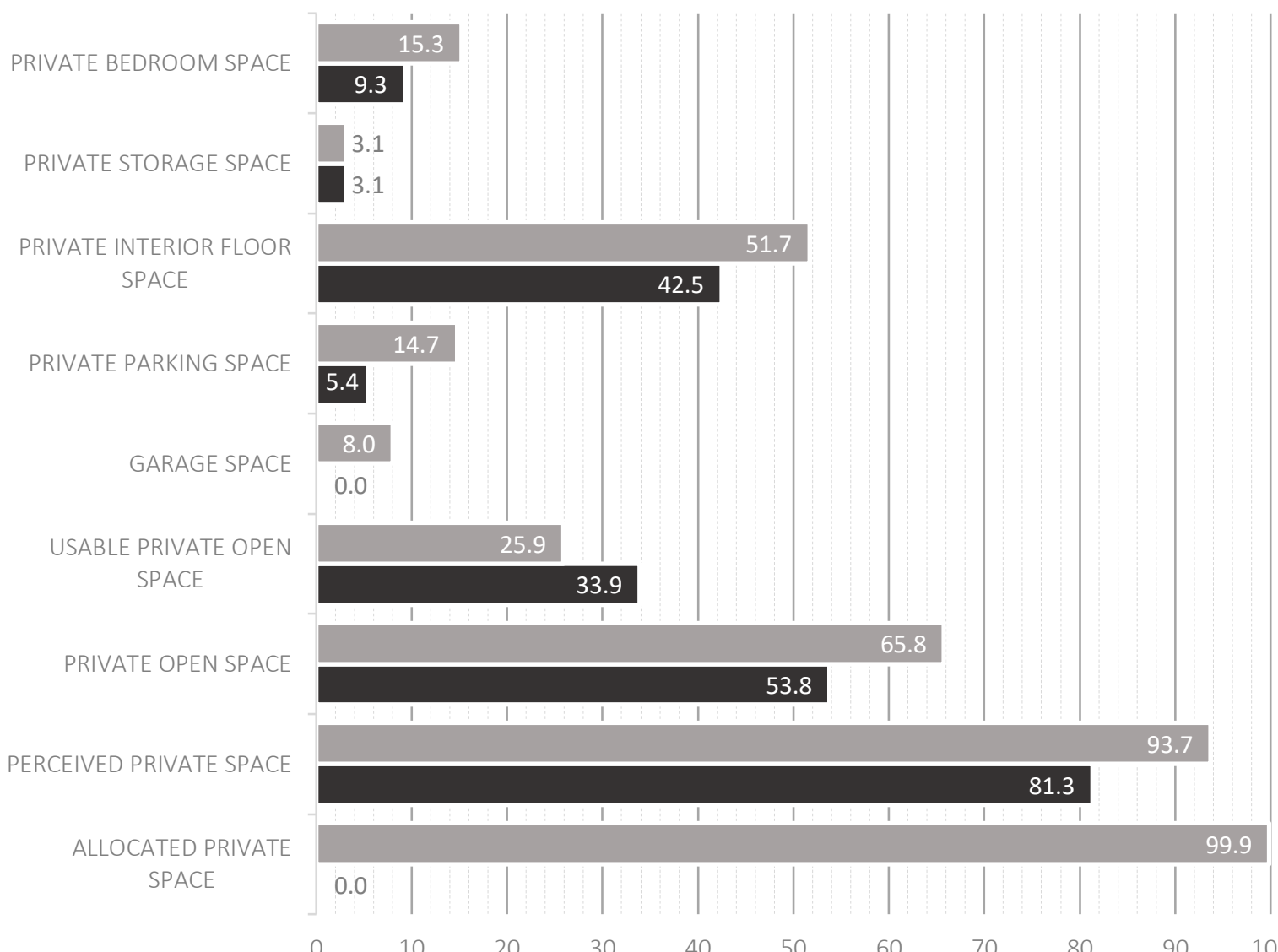

TERRITORY AREA (M2 PER PERSON)

KEY

- 55 Duke Street - Taylors Road 


\section{NET AND GROSS TERRITORY DEFINITIONS}

The definitions of net and gross territories vary greatly with a high degree of ambiguity, although typically their distinctions are focussed on the inclusion or exclusion of the "broader network of public space" (Dovey and Pafka, 2014, p. 67). Therefore, for this report net and gross territories have been defined as follows:

- Net area is divided into three categories, based on typical net area definitions. For this analysis net area is specifically based on the following three definitions; Patel's (2011, p. 585) definition of net density, Boyko's (2011, p. 6) definition of parcel or site density, and Alexander's (1993, p. 186) definition of net dwelling density. Therefore, net density is described as a measurement over the area of buildable plot areas only. Due to the scale of this analysis method and the use of a case study that is not subdivided, net areas have been further refined to allow better cross comparison between case studies as follows:

a) Net dwelling space as private space only, defined by the 'allocated private area' if applicable, otherwise as defined by the 'perceived private area'. This allows a measure of density exclusively within private space;

b) Net dwelling space as developable area only. This allows a measure of density that shows the intensity of land use including of the provision of access across the development site;

c) Net dwelling space as development area defined by legal boundaries of the lot, or combined lot when subdivision has occurred. Although this is still classified as a net measure by most, it allows a representation of the development scale density by including spaces such as shared roads which are semi-private;

- Gross area is further defined and divided into two categories, based on typical gross area definitions and the data and resources available

- Gross dwelling space as development area is defined by the legal boundaries of the lot, including half of the area of adjacent roads and a quarter of the area of adjacent intersections to incorporate the open space of infrastructure. If the perimeter roads are greater than $30.5 \mathrm{~m}$ wide, then the road area added only needs to include an area up to $15.25 \mathrm{~m}$ from the property line. This follows Alexander's $(1993$, p. 186) definition of gross residential density that includes relevant land for housing and its direct access. Hence he explains that "the omission of more than 50' [15.24m] of perimeter roads from the denominator is premised on the assumption that if the right of way is wider than 100' [30.48m], the street must also be serving other (e.g., collector or arterial) functions" (Alexander, 1993)

- Gross dwelling space as defined by the meshblocks that Statistics New Zealand (2013) collate household and resident data by. Meshblocks follow the net island and fabric territory definitions that were defined earlier, in the review section. Meshblocks are advantageous as a territory for analysis due to their descriptive, rather than prescriptive, form. Pont and Haupt (2010, p. 100) explain that "by letting the matter itself generate its boundaries, the artificial straightjacket forced upon that which is analysed is minimised." So by allowing their boundaries to be dictated by changes in density and use that already exist, the average density measures generated within are more accurate. 


\section{APPLYING NET AND GROSS TERRITORY DEFINITIONS TO THE CASE STUDIES}

Figure 1: Taylors Road net and gross measurement areas

NET AND GROSS AREAS

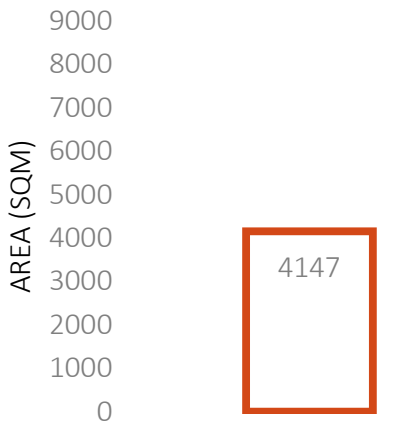

a) Net dwelling space as private space only

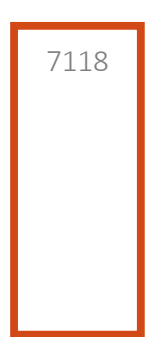

b) Net dwelling space as developable area only

Net dwelling area

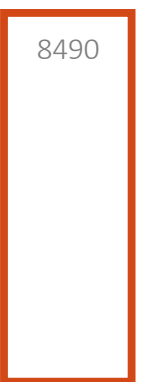

c) Net dwelling space as total development area development area (incl. half of adjacent roads)

Gross dwelling area

Figure 1 shows that the majority of space within the development is shared, rather than private space, even when developable space only is taken into account. \% of change between compared with other.

\section{TYPICAL DENSITY METRICS (POPULATIONS, DWELLINGS AND BUILDINGS)}

Now that territories have been defined, the result can be discussed in terms of typical density metrics.

\section{POPULATIONS}

Actual populations of the housing developments are not always available to access. Therefore, estimates of the populations could be developed for comparisons as follows.

- An actual population count was provided by Housing New Zealand for the selected case study developments. This is incredibly valuable information that is vital to density analysis. However, for developments that are not state housing this will be more difficult to access.

- Maximum population as designed is based on the bedroom number and size (filling all of the possible bed spaces). This was used to understand the maximum capacity of the housing development as it is designed. It is a particularly useful number for the two case studies which are analysed in this report as they are both state housing developments, hence they are likely to be filled to capacity due to the motives and design guidelines of Housing New Zealand. For private sector and local authority housing developments this value will have to be regarded differently. Private sector developments are especially varied in their occupancy due to the diverse lifestyles of residents creating a common mismatch of bedroom capacity to household size. (Allen and Bryson, 2017) Maximum capacity was assumed by including two people per double bedroom and one person per single bedroom.

- Census mesh block populations that are collected by Statistics New Zealand were also used to estimate actual populations. These provide a population count for both usual number of residents and number of residents present that night for the given area. Usual number of residents is used as it includes residents who may have been away at the time of survey. Discuss what census mesh blocks are. Discuss why bottom up not assigned territory. 
- Lastly, HEEP study data accessed from Nilesh Bakshi's thesis (2017) provides an accurate representation of New Zealand housing. (Bakshi, 2017, p. 244) The Monte Carlo method of analysis was used to select 394 separate houses for data analysis, however the data is greatly limited by the exclusion of apartments and inner-city dwellings. (Bakshi, 2017, p. 244) The house size and household size data was extracted to understand the correlations between these and to compare to the case study data.

- Monte Carlo method of analysis to gain accurate oversight of New Zealand housing sizes;

- a statistical representation of the residential building stock that identifies household sizes;

- Population limitations

However, the population in 1978 of the Taylors Road development was provided in Davey's (1978, p. 11) report, so this figure can also be used. At the time of the investigation there were 55 people housed in the development, giving an average household size of 2.8 people.

\section{INSTANCE DENSITIES}

\section{Figure X: Taylors Road instance densities}

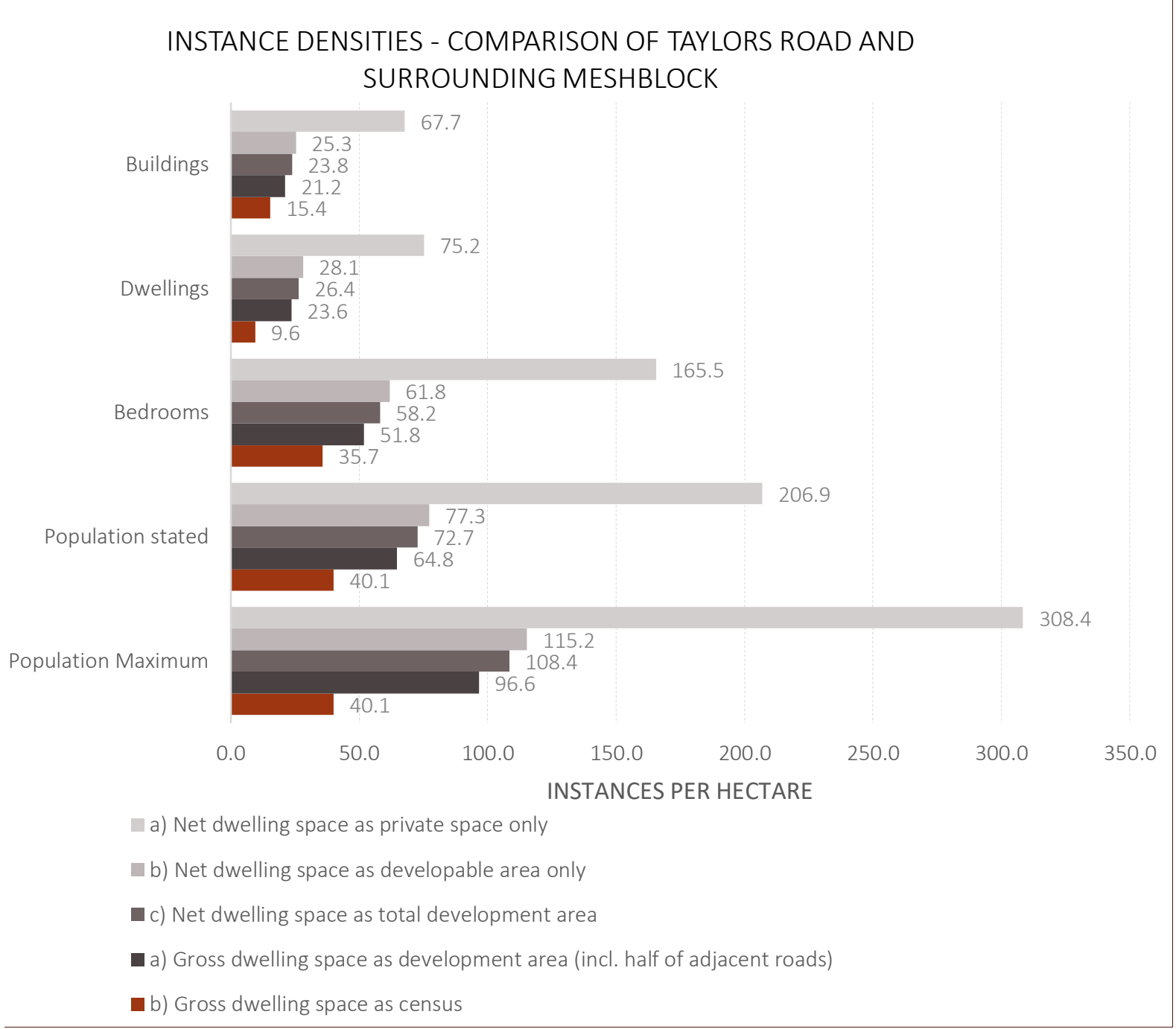


Figure X: Density instance proportions

DENSITY INSTANCE PROPORTIONS - COMPARING THE MESHBLOCK WITH THE DEVELOPMENT

Census Meshblock

Development using stated population Development using maximum population

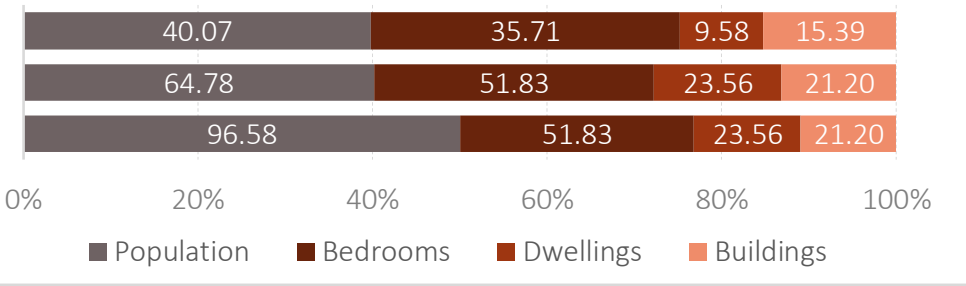

Figure 2 shows that Taylors Road has a higher instance density than its surrounding meshblock.

HOUSEHOLD SIZES

Figure X: Taylors Road household size comparisons

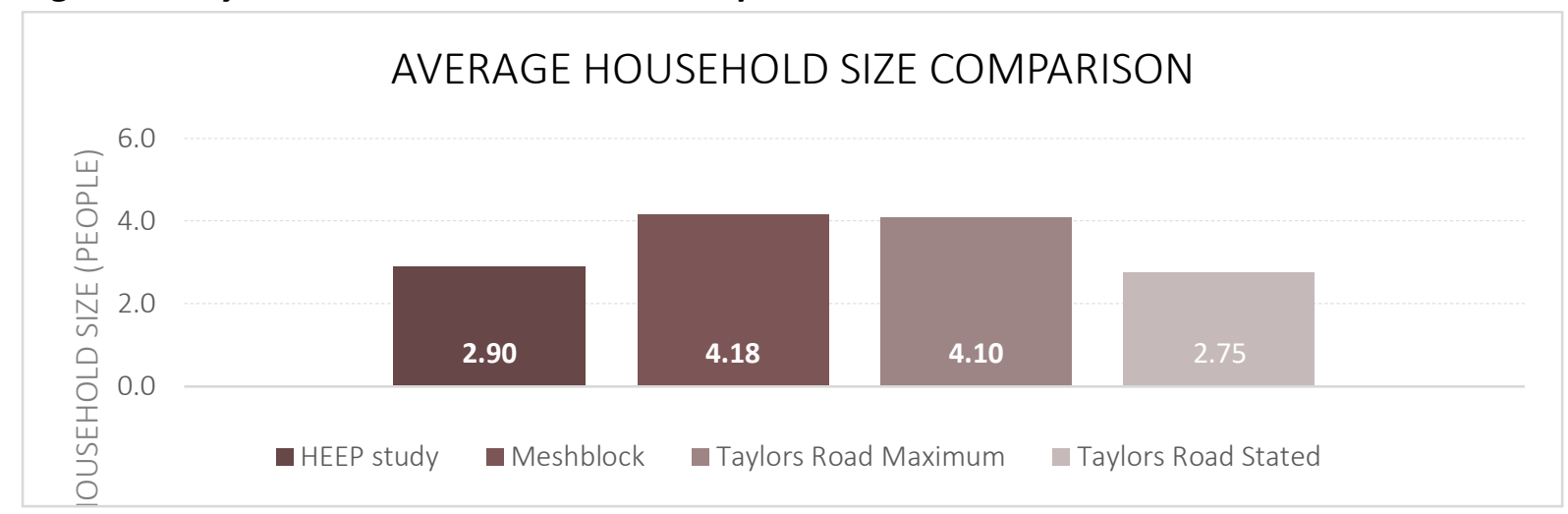

Tells us that the households are rather large for the area but doesn't really indicate density in relation to a definitive, comparative scale (such as area). This is interesting but would be much more useful with area included to compare as occupancy rate, urban footprint, internal density or external density. Then an indication of the space per person could be provided. However, it is still useful to show the household size as it mediates the relationship between built density and population density (Dovey and Pafka, 2014). 


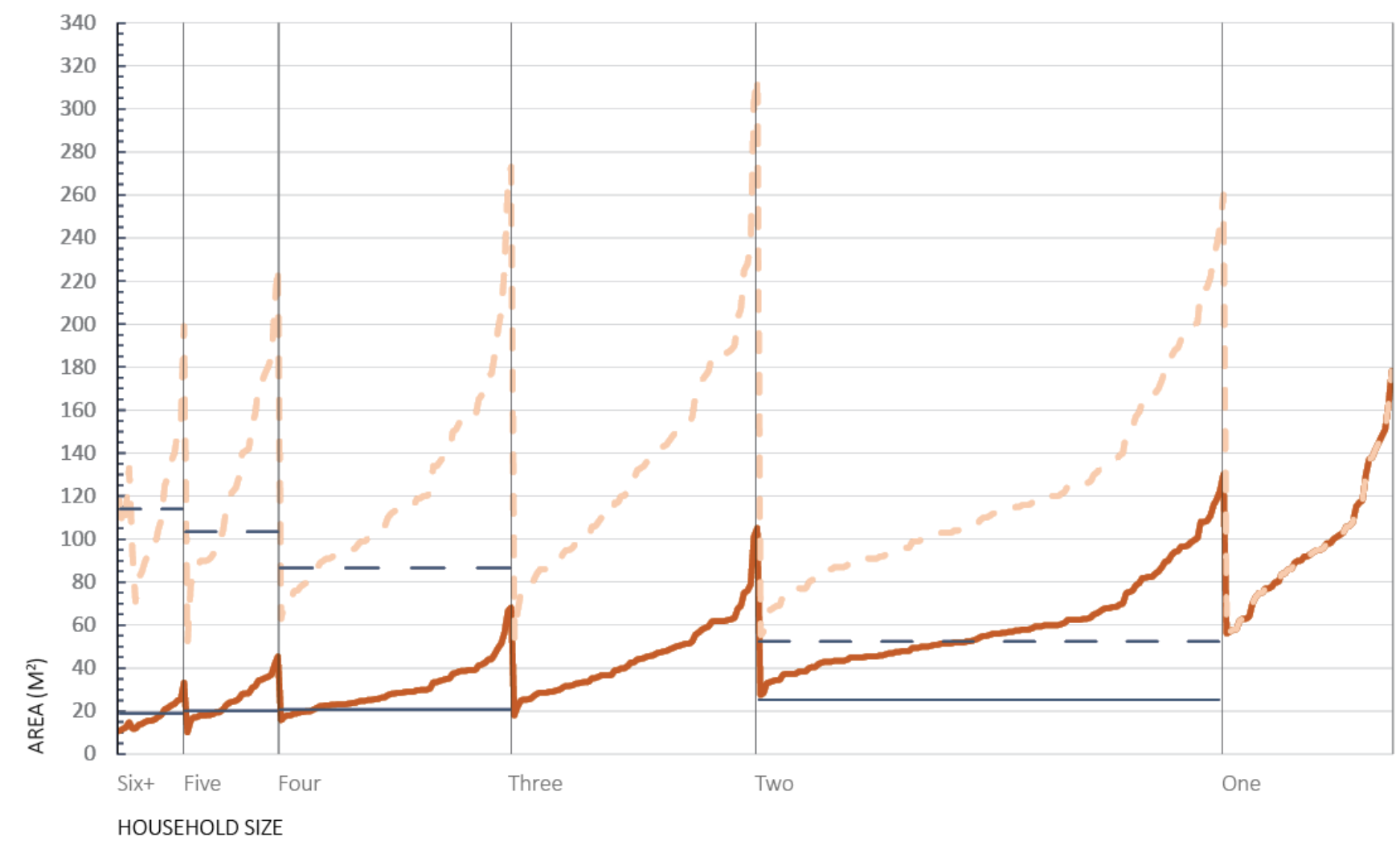

KEY

\begin{tabular}{|l|l|l|}
\hline $\begin{array}{l}\text { Household size } \\
\text { (people) }\end{array}$ & $\begin{array}{l}\text { House size } \\
\left(\mathrm{m}^{2}\right)\end{array}$ & $\begin{array}{l}\text { Occupancy rate }\left(\mathrm{m}^{2}\right. \\
\text { per person) }\end{array}$ \\
\hline 2 & 54.5 & 27.3 \\
\hline 4 & 87.4 & 21.8 \\
\hline 5 & 104.5 & 20.9 \\
\hline 6 & 114.5 & 19.1 \\
\hline
\end{tabular}

For smaller household sizes, Taylor's Road housing provides very much smaller houses compared to the rest of New Zealand. It appears that the houses are of more average size as the household size increases, however that may be because the population figure used for Taylors Road assumed the houses to be used at full capacity. It would be valuable to compare this using accurate population data. This comparison provides a valuable insight to the internal density of housing comparative to the rest of New Zealand. 
- Date of data influences the results

- Because of living space composition change in market houses especially? State houses quite similar in size over time

- Discuss comparatively, see what changes most to understand what is most interesting to measure

\section{FLOOR AREA RATIOS}

Figure x: Taylors road - FAR (floor area ratio) for different territories

Key: "Site area - Floor area

\section{Net territory a:}

Net dwelling space as private space only

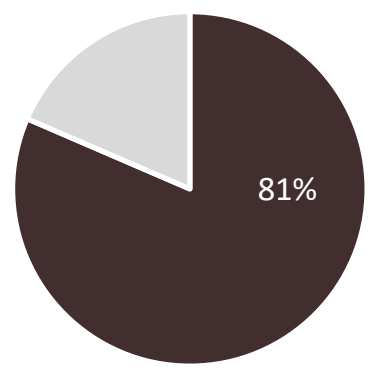

Net territory b:

Net dwelling space as

developable area only

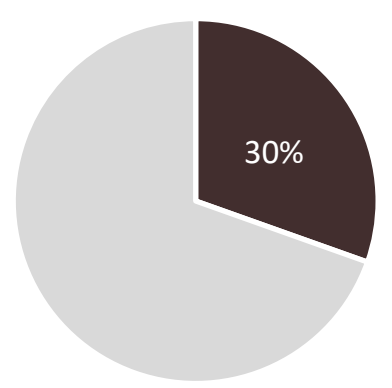

Net territory c:

Net dwelling space as total development area

\section{Gross territory a:}

Gross dwelling space as

development area (incl. half

of adjacent roads)

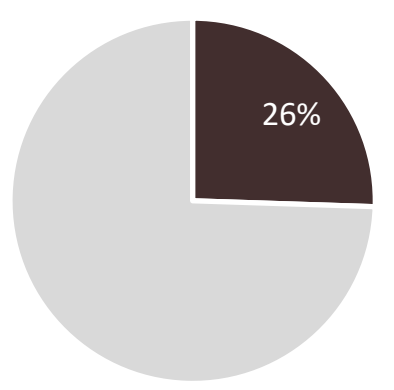




\section{DISCUSSION - MEDIUM DENSITY RESULTS}

- Per person

- Personal experience

- Compactness - how closely can we live

- Per household

- Land use and urban fabric

\section{IMPLICATIONS}

\section{FUTURE RESEARCH BASED ON FINDINGS AND METHODLOGY LIMITATIONS.}

Value judgement of what measures or what combination.

- Analysis of larger and more developments / housing to grasp the New Zealand context

- Neighbourhood and city scale density analysis

- Analysis of rural areas and densities

- Perceived densities

- Impact of media, culture and other influencing factors on perceived density e.g. leaky home crisis

- Density analysis in relation to other subject areas

- Economics e.g. market forces, affordability

- Psychology

- Sustainability

○ Housing design

- Urban design principles e.g. liveability, infrastructure and transport

- Affordability

- Construction of denser housing

- Resident demographics and satisfaction in density

- Assessment of where density changes are appropriate

- Assessment of density in relation to typology diversity

- Precise definitions of space e.g.

- Useful shared space

- Useful private outdoor space

- Developable space

- Incorporating the flexibility of spaces in the density analysis e.g. garages

\section{FINAL LIST OF LIMITATIONS}

Databases and search protocols could be expanded to include:

- Published research

- English language

- Narrative means very qualitative data, e.g. couldn't do quantitative count of method uses/mentions etc

- Varied case study sizes 


\section{REFERENCES}

\section{INTERNATIONAL QUANTIFICATION METHODS CITED}

Alexander, E.R., 1993. Density Measures: a review and analysis. Journal of Architectural and Planning Research 10, 181-202.

Boyko, C.T., Cooper, R., 2011. Clarifying and re-conceptualising density. Progress in Planning, Clarifying and re-conceptualising density 76, 1-61. https://doi.org/10.1016/j.progress.2011.07.001

Cheng, V., 2010. Understanding Density and High Density, in: Ng, E. (Ed.), Designing High-Density Cities for Social and Environmental Sustainability. Earthscan, London ; Sterling, VA, pp. 3-17.

Churchman, A., 1999. Disentangling the Concept of Density. Journal of Planning Literature 13, 389411. https://doi.org/10.1177/08854129922092478

Dovey, K., Pafka, E., 2014. The urban density assemblage: Modelling multiple measures. Urban Design International; Basingstoke 19, 66-76. http://dx.doi.org/10.1057/udi.2013.13

Patel, S., 2011. Analyzing urban layouts - can high density be achieved with good living conditions? Environment and urbanization 23, 583-595. https://doi.org/10.1177/0956247811418737

Pont, M.B., Haupt, P., 2010. Spacematrix: space, density and urban form. NAI, Rotterdam.

Rapoport, A., 1975. Toward a Redefinition of Density. Environment and Behavior 7, 133-158. https://doi.org/10.1177/001391657500700202

\section{NEW ZEALAND METRICS AND METHODS CITED}

About medium-density housing [WWW Document], n.d. . Wellington City Council. URL http://wellington.govt.nz/your-council/projects/housing-choice-and-supply/mediumdensity-housing (accessed 1.24.19).

Allen, N., Bryson, K., 2017. Defining medium-density housing (BRANZ Study Report No. SR376), Medium-density housing that meets the needs of New Zealanders. BRANZ, Wellington, New Zealand.

Boffa Miskell Ltd., 2012. Medium-density housing: Case study assessment methodology (No. ME 1083), Medium-density Housing. Ministry for the Environment, Wellington, New Zealand.

Gray, R.N., 2007. Infill housing: Residential Intensification and the Wellington Urban Development Strategy (Research). Wellington City Council, Wellington, New Zealand.

Mead, D., 2007. Intensification and the Distric Plan: Issues and Options for Facilitating and Managing Intensive Residential Development in Wellington City (Final Report No. 1574). Wellington City Council, Wellington, New Zealand.

Moore, C., 2017. Backyard death in Auckland. X-Section 7, 71-77.

Sharpin, A.B., 2006. Urban Development Strategy Working Paper 6: The Social and Environmental Effects of Residential Infill Development in New Zealand - A Literature Review.

The Department of Internal Affairs, 2008. Building Sustainable Urban Communities - Glossary [WWW Document]. Te Tari Taiwhenua | Department of Internal Affairs. URL https://www.dia.govt.nz/diawebsite.nsf/wpg_URL/Resource-material-Building-SustainableUrban-Communities-Glossary?OpenDocument (accessed 11.28.18). 


\section{CASE STUDY REFERENCES}

Auckland Design Manual, n.d. Duke Street Terrace Housing [WWW Document]. Auckland Design Manual. URL http://www.aucklanddesignmanual.co.nz/sites-and-buildings/terraces/casestudies/39-55-duke-street (accessed 2.22.19).

Davey, J.A., 1978. Medium density housing and its place in the urban environment: a report for the Urban Affairs Committee of the Environmental Council.

Housing New Zealand Corporation, 2014. Taylor's Ave state houses [WWW Document]. NZ History. URL https://nzhistory.govt.nz/media/photo/taylors-ave (accessed 2.22.19).

Statistics New Zealand, 2013. 2013 Census meshblock dataset [WWW Document]. Stats NZ. URL http://archive.stats.govt.nz/Census/2013-census/data-tables/meshblock-dataset.aspx (accessed 1.24.19).

\section{OTHER REFERENCES}

Auckland Council, n.d. Private outdoor spaces [WWW Document]. Auckland Design Manual. URL http://www.aucklanddesignmanual.co.nz/sites-and-buildings/terraces/guidance/outdoorspaces/private-outdoor-spaces (accessed 1.31.19a).

Auckland Council, n.d. Communal outdoor spaces [WWW Document]. Auckland Design Manual. URL http://www.aucklanddesignmanual.co.nz/sites-and-buildings/terraces/guidance/outdoorspaces/private-outdoor-spaces\#/sites-and-buildings/terraces/guidance/outdoorspaces/communal-outdoor-spaces (accessed 1.31.19b).

Bakshi, N., 2017. A life cycle analysis of living: Measuring behaviour and the impact of dwelling rather than the dwelling alone (Doctoral Thesis). Victoria University of Wellington, Wellington, New Zealand.

Betanzo, M., 2007. Pros and cons of high-density urban environments | BRANZ Build. BUILD magazine, BUILD magazine.

Garcia, E.J., Vale, B., 2017. Compact Cities, in: Unravelling Sustainability and Resilience in the Built Environment. Routledge, Taylor \& Francis Group, London ; New York, pp. 116-140.

Hall, A.C., 1987. The Provision of Private Open Space for Dwellings: An Assessment of the Policies of Local Planning Authorities. The Town Planning Review 58, 183-197.

Hall, T., 2008. Where have all the gardens gone? Australian Planner 45, 30-37. https://doi.org/10.1080/07293682.2008.9982633

The Institute for Local Government, 2010. Understanding the Basics of Land Use and Planning Glossary of Land Use and Planning Terms (Glossary). The Institute for Local Government, California, United States of America.

Wellington City Council, 2013. Appendix 7: Johnsonville Medium Density Residential Area Design Guide (Design Guide Appendix No. 7), District Plan. Wellington City Council, Wellington, New Zealand. 


\section{APPENDIX}

\section{APPENDIX 1 - SUMMARIES OF KEY LITERATURE PRIORITY READING FROM INTERNATIONAL LITERATURE}

Dovey, K., Pafka, E., 2014. The urban density assemblage: Modelling multiple measures. Urban Design International; Basingstoke 19, 66-76. http://dx.doi.org/10.1057/udi.2013.13

This article proposes an integrative approach towards conceptualising urban density, by rethinking urban density as an assemblage. Considerable research has produced a broad range of density definitions for the urban context; Building bulk, floor space and open space ratios, densities of dwellings, people and jobs, measured and perceived densities and interior and exterior densities, which can all be either net or gross. The multitude of density concepts that have been produced are inadequate in providing insight to the urban situation when they are isolated from each other.

Discussions of urban density have long been central to theories relating urban form to city life. Both maximum and minimum measures of density have been linked to qualitative aspects of cities including health, safety, creativity, vitality and sustainability. Extensive research has produced a multiplicity of density concepts: densities of building bulk and floorspace; densities of dwellings, people and jobs; measured and perceived densities; interior and exterior; net and gross. From these are derived various density controls: floor area ratios, building envelopes, coverage and open space ratios. Despite research and practice of this kind, the modelling of interconnections between different concepts and measures has proven difficult. This article proposes an integrative approach towards conceptualising urban density that seeks to clarify and to link key concepts within a loose framework of assemblage theory. In this model three fields of density measures - buildings, populations and open space - are integrated and related to questions of scale and urban intensity. Examples of suburban, urban, high-rise and informal morphologies are modelled to show how different density profiles emerge according to different measures. The model provides a basis for re-thinking density as a multiplicitous assemblage and in a manner applicable to any urban morphology.

Berghauser Pont, M., 2010. Spacematrix: space, density and urban form / Meta Berghauser Pont ; Per Haupt. NAI, Rotterdam.

Spacematrix explores the potential of urban density as a tool for urban planning and design. The authors' fascination with density is not primarily normative, making no claim to know which density is best, but is driven by the desire to understand the relational logic between density, urban form and performance. This is a prerequisite for understanding and successfully predicting the effects of specific designs and planning proposals. The focus of attention is the relationship between types of urban environment and data such as amount, size, physical properties and economic values. The book will also be used by the Bachelor's, Master's and other post-graduate programmes within the Faculty of Architecture at Delft University of Technology (TU Delft).

Cheng, V., 2010. Understanding Density and High Density, in: Ng, E. (Ed.), Designing High-Density Cities for Social and Environmental Sustainability. Earthscan, London ; Sterling, VA, pp. 3-17. 
The word 'density', although familiar at first glance, is a complex concept upon closer examination. The complexity mainly stems from the multitude of definitions of the term in different disciplines and under different contexts. This chapter attempts to untangle the intricate concepts of density according to two perspectives - namely, physical density and perceived density. A thorough comprehension of these two distinct concepts of density will serve as a basis for understanding the meaning of high density. Hopefully, this chapter will establish the ground for the discussions in the later chapters on the design of high-density cities with respect to the timeliest social and environmental issues.

Rapoport, A., 1975. Toward a Redefinition of Density. Environment and Behavior 7, 133-158. https://doi.org/10.1177/001391657500700202

The concept of density is of central importance in planning, urban design and architecture. There is an extensive literature on it and much discussion of the merits or demerits of specific densities and comparisons of them. It is my suggestion that at the moment density is not a very useful concept in human terms because it is seen largely as a matter of number of people per unit area and this is not a very useful approach. It seems necessary to develop some new conceptual approaches to the problem which would enable a redefinition of the term and hence would increase its usefulness. In this essay I will re-examine the concept of density and suggest some possible guidelines for a redefinition.

Patel, S., 2011. Analyzing urban layouts - can high density be achieved with good living conditions? Environment and urbanization 23, 583-595. https://doi.org/10.1177/0956247811418737

The purpose of this paper is to present a new form of chart, which clarifies the interrelationships between six fundamental urban design parameters that affect the quality and character of any urban layout. These parameters are: built-up area per capita; public ground area per capita (which includes streets and parks); plot factor (the ratio of land area given over to private development to land area available for public use, including that needed for circulation and area available for sport, recreation and public amenities (schools, hospitals, public toilets); floor space index (ratio of built-up area to buildable plot area); net density (population divided by the sum of all buildable plot areas); and gross density (population divided by total area). Mapping these six parameters in a chart shows the complicated tradeoffs between one desirable feature and another, including combinations that show that higher densities do not necessarily mean small accommodation and inadequate public space - but they do mean high-rise, and there are severe limits on how high densities can go. The paper also plots diagrams that show the values of these parameters for existing localities in New York, Mumbai (including Dharavi) and Delhi. These diagrams are examples. With more data and more diagrams we might reach a better understanding of what particular values or combinations of values for these parameters we should aim for when designing a new development or modifying an old one. We might also understand the values or combinations of values that we should avoid.

Alexander, E.R., 1993. Density Measures: a review and analysis. Journal of Architectural and Planning Research 10, 181-202.

Perceived density, the object of design professionals' interventions, is the result of several kinds of density. Measured density is one of these, and is expressed in density measures which 
are here related to a set of clear definitions. Studies of density measures, including perceptions and behaviour, land economics, applications and problems, planning descriptions and prescriptions, and urban form effects, are reviewed. An analysis of the relationship between density and urban form uses four dwelling types: single family detached, row housing, low-rise garden apartments, and high-rise. The conclusions suggest some relationships between densities and dwelling types and other contributing factors.

Garcia, E.J., Vale, B., 2017. Compact Cities, in: Unravelling Sustainability and Resilience in the Built Environment. Routledge, Taylor \& Francis Group, London ; New York, pp. 116-140.

In this timely book, Emilio Jose Garcia and Brenda Vale explore what sustainability and resilience might mean when applied to the built environment. Conceived as a primer for students and professionals, it defines what the terms sustainability and resilience mean and how they are related to each other and to the design of the built environment. After discussion of the origins of the terms, these definitions are then compared and applied to case studies, including Whitehill and Bordon, UK, Tianjin Eco-city, China, and San Miguel de Tucuman, Argentina, which highlight the principles of both concepts. Essentially, the authors champion the case that sustainability in the built environment would benefit from a proper understanding of resilience.

Boyko, C.T., Cooper, R., 2011. Clarifying and re-conceptualising density. Progress in Planning, Clarifying and re-conceptualising density 76, 1-61. https://doi.org/10.1016/j.progress.2011.07.001

As a spatial concept, density is a useful tool in predicting and controlling land use. However, policymakers, practitioners, academics and citizens are often uncertain about how density, and especially higher densities, can be best utilised to create and nurture the design of urban environments. Barriers related to definitions, calculations, concepts and correlations with relevant issues prevent people from understanding density beyond a simple ratio of units to area. More needs to be done to show that density plays a key role in planning, architecture and urban design, and that discussions of density cannot be done in isolation of a whole host issues found in the built and natural environment. To that end, this paper aims to clarify some of the issues surrounding density, particularly about available definitions, calculating terms, the advantages and disadvantages of increasing densities in cities and uncovering relationships between density and issues pertinent to the design of urban environments. With these relationships in mind, a new way of visualising density is then offered-through a taxonomy of density-that categorises density into its component parts, allowing scholars, policymakers and practitioners to understand what aspects of density have been examined and what gaps are still present. Finally, a re-conceptualisation of density is presented, illustrating that density is more than a quantitative calculation that exists on its own; rather, for density to be considered as an integral part of the urban environment, both 'hard' (i.e., quantitative) and 'soft' (i.e., qualitative, contextual) elements must be included.

Churchman, A., 1999. Disentangling the Concept of Density. Journal of Planning Literature 13, 389411. https://doi.org/10.1177/08854129922092478

At first glance, the concept of density is wonderfully appealing to planners. It is an objective, quantitative, and, by itself, neutral term. However, a second and third glance reveals that it is a very complex concept. Some of the complexity is inherent to the nature of the phenomena 
associated with density, but part of the complexity stems from the different ways in which density is defined and used in different countries and different disciplines. This review of the literature presents this complexity in an attempt to contribute to a better understanding of the concept and a more careful approach to its use. The review includes both academic and practice literature from the planning, urban studies, and environment-behavior disciplines and selected planning documents from countries around the world.

\section{PRIORITY READING FROM NEW ZEALAND LITERATURE}

Allen, N., Bryson, K., 2017. Defining medium-density housing (BRANZ Study Report No. SR376), Medium-density housing that meets the needs of New Zealanders. BRANZ, Wellington, New Zealand.

There are many definitions of medium-density housing (MDH) in use in New Zealand. This report reviews the existing definitions and suggests a working definition for the purposes of BRANZ's MDH research programme. It then reviews the New Zealand MDH literature in detail and describes the common typologies currently provided in the New Zealand market. 